Supporting Information for

\title{
Discovery and Biosynthesis of Streptosactin, a Sactipeptide with an Alternative Topology Encoded by Commensal Bacteria in the Human Microbiome
}

\author{
Leah B. Bushin, ${ }^{\dagger}$ Brett C. Covington, ${ }^{\dagger}$ Britta E. Rued, ${ }^{\ddagger}$ Michael J. Federle, ${ }^{\ddagger}$ and \\ Mohammad R. Seyedsayamdost ${ }^{\dagger, \psi_{,}}$
}

${ }^{\dagger}$ Department of Chemistry, Princeton University, Princeton, New Jersey, United States

‡Department of Medicinal Chemistry \& Pharmacognosy, University of Illinois at Chicago, Chicago, Illinois, United States

\&Department of Molecular Biology, Princeton University, Princeton, New Jersey, United States

*Correspondence: mrseyed@princeton.edu 


\section{Materials}

All materials were purchased from Millipore-Sigma or Fisher Scientific unless otherwise specified. Cloning reagents were purchased from New England BioLabs (NEB) as were Endoproteinases AspN and Trypsin-Ultra (Mass Spectrometry Grade). Codon-optimized gene fragments were purchased from Integrated DNA Technologies (IDT). DNA oligos were purchased from IDT or Sigma. N-Fmoc- $\alpha-{ }^{2} \mathrm{H}_{2}-\mathrm{Gly}, \mathrm{N}-\mathrm{Fmoc}-\alpha-{ }^{2} \mathrm{H}-\mathrm{L}-\mathrm{Ala}$, and N-Fmoc- $\beta-{ }^{2} \mathrm{H}_{3}-\mathrm{L}-\mathrm{Ala}$ were purchased from CDN Isotopes. ${ }^{13} \mathrm{C}_{2},{ }^{15} \mathrm{~N}_{1}-\mathrm{Fmoc}-\mathrm{Gly}$ and ${ }^{13} \mathrm{C}_{3}-\mathrm{N}-\mathrm{Fmoc}-\mathrm{L}-$ Ala were purchased from Cambridge Isotope Laboratories. Streptococcus thermophilus JIM 8232 was kindly provided by Christine Delorme (INRA, Micalis Institut, Jouy-en-Josas, France).

\section{General Procedures}

UV-vis spectra were acquired on a Cary 60 UV-visible spectrophotometer (Agilent). Low resolution high-performance liquid chromatography-mass spectrometry (HPLC-MS) analysis was performed on an Agilent instrument consisting of a liquid autosampler, a 1260 Infinity Series HPLC system coupled to a diode array detector, and a 6120 Series ESI mass spectrometer. A Phenomenex Luna C18 column ( $3 \mu \mathrm{m}, 4.6 \mathrm{~mm} \times 100 \mathrm{~mm}$ ) was used with a flow rate of $0.5 \mathrm{~mL} / \mathrm{min}$ and the following elution plan: $8 \% \mathrm{MeCN}$ in water for $5 \mathrm{~min}, 8-60 \% \mathrm{MeCN}$ over $15 \mathrm{~min}, 60-100 \% \mathrm{MeCN}$ over $5 \mathrm{~min} . \mathrm{H}_{2} \mathrm{O}$ and MeCN contained $0.1 \%(\mathrm{v} / \mathrm{v}$ ) formic acid (FA).

HPLC-coupled high-resolution (HR) MS and tandem HR-MS were carried out on an Agilent 6540 accurate-mass quadrupole time-of-flight (Qtof) MS instrument, consisting of an automated liquid sampler, a 1260 Infinity Series HPLC system, a diode array detector, a JetStream ESI source, and the 6540 Series Qtof. Samples from enzymatic assays were resolved on an Agilent Eclipse Plus C18 column $(3.5 \mu \mathrm{m}, 4.6 \times 100 \mathrm{~mm})$ operating at 0.6 $\mathrm{mL} / \mathrm{min}$. The mobile phases consisted of $\mathrm{H}_{2} \mathrm{O}$ and $\mathrm{MeCN}(+0.1 \% \mathrm{FA})$. Elution was performed with an isocratic step of $8 \%$ MeCN for 8 min followed by gradient steps of $8-60 \%$ MeCN over 12 min, and 60-95\% MeCN over 4 min. Products of protease cleavage reactions were resolved on a Phenomenex Jupiter $\mathrm{C} 18300 \AA$ ( $5 \mu \mathrm{m}, 4.6 \times 150 \mathrm{~mm})$ column operating at $0.6 \mathrm{~mL} / \mathrm{min}$ using the same elution program. Analysis of streptosactin was carried out on a Phenomenex Luna Omega Polar column $(5 \mu \mathrm{m}, 4.6 \times 100 \mathrm{~mm})$ operating at $0.75 \mathrm{~mL} / \mathrm{min}$ with $\mathrm{H}_{2} \mathrm{O}$ and $\mathrm{MeCN}$ $(+0.1 \% \mathrm{FA})$ as mobile phase. Elution was carried out isocratically with $0 \% \mathrm{MeCN}$ for $3 \mathrm{~min}$, followed by gradients of $0-12 \% \mathrm{MeCN}$ over $8 \mathrm{~min}$, and $12-100 \% \mathrm{MeCN}$ over $2 \mathrm{~min}$.

HPLC purifications were carried out on an Agilent 1260 Infinity Series analytical or preparative HPLC system equipped with a temperature-controlled column compartment, a diode array detector, and an automated fraction collector. The analytical system was also equipped with an automated liquid sampler.

Nuclear magnetic resonance (NMR) and electron paramagnetic resonance (EPR) spectra were acquired at the Princeton University Department of Chemistry Facilities. $1 \mathrm{D}{ }^{13} \mathrm{C}$ NMR spectra were collected in a DCH double resonance cryoprobe of a Brucker Avance III 500 $\mathrm{MHz}$ spectrometer. 1D ${ }^{1} \mathrm{H}$ and 2D NMR spectra were collected in the triple resonance cryoprobe of a Bruker Avance III $800 \mathrm{MHz}$ NMR spectrometer. Full-length GggA peptide samples were prepared in $20 \mathrm{mM}$ potassium phosphate buffer in $\mathrm{D}_{2} \mathrm{O}$ or $9: 1 \mathrm{H}_{2} \mathrm{O} / \mathrm{D}_{2} \mathrm{O}$ in a $2.5 \mathrm{~mm}$ diameter tube. The streptosactin sample was prepared in $\mathrm{D}_{2} \mathrm{O}$ in a $3.0 \mathrm{~mm}$ diameter tube. All NMR data were analyzed with MestReNova software. CW X-band EPR spectra were recorded at $10 \mathrm{~K}$ on a Bruker EMXplus EPR spectrometer equipped with an Oxford liquid Helium cryostat and the following parameters: power, $50 \mu \mathrm{W}$; modulation amplitude, $8 \mathrm{G}$; modulation frequency, 100 kHz; center field, 3500 G; sweep width, 1500 G; sweep time, 60 s; time constant 5.12 s. EPR spectra were simulated using the "pepper" utility from the EasySpin software package. 


\section{General Molecular Biology/Cloning Procedures}

Genomic DNA from S. thermophilus JIM 8232 was isolated using the Wizard Genomic DNA Purification Kit (Promega). PCR reactions were performed with Q5 High Fidelity DNA polymerase (NEB) in FailSafe PreMix Buffer D (Epicenter) in a CFX96 thermocyler (Bio-Rad). PCR products were purified using the Qiagen PCR Purification Kit. DNA fragments and plasmids were digested with restriction enzymes and purified using the Qiagen Gel Extraction Kit. Linearized vectors were typically treated with Shrimp Alkaline Phosphotase (rSAP) prior to ligation or DNA assembly. All ligation reactions were performed with T4 DNA Ligase and all DNA assemblies were performed with HiFi DNA Assembly Master Mix (NEB). All cloning reagents were used according to instructions. Chemically competent $E$. coli $\mathrm{DH} 5 \alpha$ cells were transformed with ligation or HiFi mixtures by heat-shock and plated onto LB-agar containing the appropriate antibiotic. Assembled plasmids were confirmed by Sanger sequencing.

\section{Construction of pET-28b(+)_gggB}

The gggB gene (IMG Gene ID: 651282557) was PCR-amplified from genomic DNA with primers gggB_JIM8232_F (Ndel) and gggB_JIM8232_R (BamHI) (Table S3) and digested with the restriction enzymes $\mathrm{Ndel}$ and $\mathrm{BamHI}$. Vector $\mathrm{pET}-28 \mathrm{~b}(+)$ was linearized by digestion with the same restriction enzymes. Vector and insert were joined by ligation.

\section{Construction of pRSFDuet-1_6HMBPgggA_gggB}

The $g g g A$ and $g g g B$ genes were obtained as synthetic DNA fragments, codon-optimized for expression in E. coli. The gggB gene was PCR-amplified from its synthetic DNA fragment using primers Duet_gggB_F (Ndel) and Duet_gggB_R (Xhol) (Table S3). The PCR product was then digested with $\mathrm{Ndel}$ and $\mathrm{Xhol}$ and ligated into the second multiple cloning site (MCS2) of pRSFDuet-1, which had been linearized using the same restriction enzymes. The pRSFDuet-1 vector containing the gggB gene inside MCS2 was then digested with $\mathrm{Ncol}$ and BamHI, opening up MCS1 into which a DNA fragment encoding a 6HMBP tag was ligated, yielding plasmid pRSFDuet-1_6HMBP_gggB (Table S1). This DNA fragment, which included a C-terminal linker region with a HRV3C cleavage site, had been excised from vector pBAD_6HMBPP_HTFLAG using restriction enzymes $\mathrm{Ncol}$ and BamHI. Next, the gggA gene was PCR-amplified from its synthetic DNA fragment using primers Duet_gggA_F (BamHI) and Duet_gggA_R (Pstl) (Table S3). The resulting PCR product was then digested with restriction enzymes BamHI and Pstl as was pRSFDuet-1_6HMBP_gggB. These digestion products were then joined in a ligation reaction, providing the final construct.

\section{Construction of pRSFDuet-1_6HMBPgggA-nx_gggB where $\mathrm{n}=1,2$ or 3}

The $g g g A-1 \mathrm{x}$ fragment was PCR-amplified from the $g g g A$ synthetic fragment using primers Duet_gggA_F and Duet_gggA-1x_R (Table S3). The resultant $g g g A-1 x$ PCR fragment was then used as a template in a PCR reaction with primers Duet_gggA_F and $g g g A-2 x \_R$ to generate the $g g g A-2 x$ fragment. Finally, the $g g g A-2 x$ PCR fragment was used as a template in a $\mathrm{PCR}$ reaction with primers $g g g A \_\mathrm{F}$ and Duet_gggA-3x_R to generate the $g g g A-3 \mathrm{x}$ fragment. Each PCR fragment was then incubated with BamHI/Pstl-digested pRSFDuet-1_6HMBP_gggB (see above), in a HiFi Assembly reaction, generating the respective $1 \mathrm{x}, 2 \mathrm{x}$, or $3 \mathrm{x}$ constructs.

\section{Construction of pRSFDuet-1_6HMBPgggA-4x_gggB}

Plasmid pRSFDuet-1_6HMBPgggA-3x_gggB (see above) was cleaved with Notl, removing a short region of the 3 '-end of $g g g A-3 x$. A small DNA fragment (103 bp) to replace of 
the excised region was synthesized by PCR using two primers with 3 '-ends complimentary to one another and distinct 5'-overhangs, which included appropriate overlap regions for DNA assembly. This fragment encoding a modified C-terminal region of GggA was then joined with the Notl digested plasmid using HiFi Assembly.

\section{Construction of pRSFDuet-1_6HMBPgggA-3x,C31S_gggB}

For making the construct encoding the GggA-3x variant with a Cys-to-Ser substitution at position 31 (numbering references GggA peptide only, starting with Met 1), the same procedure as described above for the pRSFDuet-1_6HMBPgggA-3x_gggB construct was followed, except that primer Duet_gggA-x3,C31S_R was used as the reverse primer in the PCR reaction.

\section{Construction of pRSFDuet-1_6HMBPgggA-R22_gggB}

A modified gggA gene encoding an Arg (codon AGG) residue between lle21 and Asn22 was synthesized by PCR using two long primers ( 90 bp) with 3'-ends complimentary to one another. The primers also included appropriate 5'-overhang regions for DNA assembly. This gggA-R22 fragment was then joined with BamHI/Pstl-digested pRSFDuet-1_6HMBP_gggB in a HiFi reaction.

\section{Expression, Purification, and Reconstitution of GggB}

Expression, purification, and reconstitution of GggB was carried out using previously published procedures without modifications. ${ }^{1}$ Purified $\mathrm{GggB}$ was quantified using the method reported by Barr et al. ${ }^{2}$ GggB was anaerobically reconstituted with 10 -fold excess Fe(II) and 10fold excess $\mathrm{Na}_{2} \mathrm{~S}$, as per reported procedures. ${ }^{1}$

\section{Synthesis of GggA Substrates}

GggA substrates were prepared by Fmoc-based solid phase peptide synthesis (SPPS) on a preloaded $\mathrm{H}$-Arg(Pbf)-HMPB-ChemMatrix resin using a Liberty Blue automated peptide synthesizer equipped with a Discover microwave module (CEM). The deprotection solution consisted of $10 \%$ piperazine (w/v) in a 10:90 solution of EtOH:NMP (N-methylpyrrolidine) supplemented with $0.1 \mathrm{M} \mathrm{HOBt}$ (1-hydroxybenzotriazole). The activator solution consisted of 0.5 M DIC (N,N'-diisopropylcarbodiimide) in DMF and activator base solution of $1.0 \mathrm{M}$ Oxyma with 0.1 M DIPEA in DMF. A typical coupling cycle used 5-6 equiv. of amino acid and 5-6 equiv. of coupling reagent. Residues 21-35 were double-coupled. The synthesis was performed on a 100 $\mu \mathrm{mol}$ scale for wt GggA and on a $50 \mu \mathrm{mol}$ scale for GggA variants. Upon completion of the synthesis, the resin was removed from the reaction vessel and transferred to an Econo-Pac column (Bio-Rad). The resin was washed several times with DMF, followed by DCM, and dried thoroughly under vacuum. The peptide was cleaved from the resin by incubation with freshly prepared cleavage cocktail ( $5 \mathrm{~mL}$ per $100 \mathrm{mg}$ resin) consisting of $92.5 \%$ TFA, $2.5 \% \mathrm{H} 2 \mathrm{O}, 2.5 \%$ TIS (triisopropylsilane), and 2.5\% DODT (2,2'-(ethylenedioxy)diethanethiol). The reaction was stirred for $1-3 \mathrm{~h}$ at room temperature. The mixture was drained from the reaction tube and the resin then rinsed several times with TFA. The filtrate and rinses were combined and subsequently concentrated by evaporation of TFA under a stream of $\mathrm{N}_{2}$. The peptide was then precipitated by addition of 10 volumes of ice-cold diethyl ether and collected by centrifugation (4000g, $10 \mathrm{~min}, 4^{\circ} \mathrm{C}$ ). The ether was poured off and the peptide was dried overnight in a fume hood. 


\section{Purification of GggA Substrates}

Crude peptide was dissolved in a few $\mathrm{mL}$ of DMF and purified by semi-preparative HPLC. Separation was carried out an Agilent Eclipse XDB-C8 column (5 $\mu \mathrm{m}, 9.4 \times 250 \mathrm{~mm})$, operating at $2.5 \mathrm{~mL} / \mathrm{min}$ with water and $\mathrm{MeCN}$ as mobile phases. Both solvents contained $0.1 \%$ FA. The elution method consisted of the following steps: $15 \% \mathrm{MeCN}$ in water for $5 \mathrm{~min}, 15-80 \%$ MeCN over 20 minutes, and $80-100 \%$ MeCN over 5 min. GggA eluted around 13.6-14.1 min.

\section{Enzymatic Activity Assays}

Enzymatic assays were performed in an inert atmosphere (glovebox). GggA peptides were transported into the glovebox as lyophilized material and resuspended in reconstitution buffer to give a ( 2-4 mM solution). Sodium dithionite (DT), dithiothreitol (DTT), and SAM were also transported into the glovebox as powders and prepared as stock solutions in water or assay buffer inside the box. Reactions were typically carried out in $0.5 \mathrm{~mL}$ microcentrifuge tubes on a $30 \mu \mathrm{L}$ scale with final concentrations of $2 \mathrm{mM}$ DTT, $5 \mathrm{mM}$ DT, $0.5 \mathrm{mM}$ GggA, $30 \mu \mathrm{M} \mathrm{GggB}$, and $1 \mathrm{mM}$ SAM. Reactions were incubated overnight. At the end of the incubation period, the reaction tubes were taken out of the glovebox and heated at $95^{\circ} \mathrm{C}$ for $3 \mathrm{~min}$. Precipitated protein was removed by centrifugation. Samples were then diluted with an equal volume $\mathrm{H}_{2} \mathrm{O}(+0.1 \%$ FA) and directly analyzed by HPLC-Qtof-MS as described above. Alternatively, for detection of 5'-dA, quenched reactions were diluted by addition of $500 \mu \mathrm{L} \mathrm{H}_{2} \mathrm{O}(+0.1 \% \mathrm{FA})$ and subjected to solid-phase extraction using a Phenomenex Strata C18-E cartridge (50 mg, bed volume $=75$ $\mu \mathrm{L}$ ). The resin was washed and equilibrated with $\mathrm{MeCN}$ and $\mathrm{H}_{2} \mathrm{O}$, respectively, prior to sample application. Following sample loading, the resin was washed with $\mathrm{H}_{2} \mathrm{O}(300 \mu \mathrm{L})$ and eluted with $15 \% \mathrm{MeCN}(750 \mu \mathrm{L})$, then with $60 \% \mathrm{MeCN}(750 \mu \mathrm{L})$. All solvents contained $0.1 \% \mathrm{FA}$. The eluted fractions were dried in vacuo, resuspended in a $60 \mu \mathrm{L} 15 \% \mathrm{MeCN}(+0.1 \% \mathrm{FA})$ and analyzed by HPLC-Qtof-MS.

\section{Large-Scale Enzymatic Reactions}

The concentrations of all components were identical to those in the analytical-scale assays described above, but the total reaction volume was increased from $30 \mu \mathrm{L}$ to $3.0 \mathrm{~mL}$ for the ${ }^{13} \mathrm{C}_{2},{ }^{15} \mathrm{~N}_{1}$-G34-GggA substrate and to $2.0 \mathrm{~mL}$ for the ${ }^{13} \mathrm{C}_{3}-\mathrm{A} 28-\mathrm{GggA}$ substrate. Reactions were incubated for $48 \mathrm{~h}$, quenched with heat and clarified by centrifugation.

\section{Isolation of GggA Peptides from Large-Scale Reactions}

Analytical HPLC was used to purify reacted ${ }^{13} \mathrm{C}_{2},{ }^{15} \mathrm{~N}_{1}-\mathrm{G} 34-\mathrm{GggA}$. The clarified solution was injected onto a Phenomenex Jupiter C18 $300 \AA$ column $(5 \mu \mathrm{m}, 150 \times 4.6 \mathrm{~mm})$ operating at a flow rate of $0.6 \mathrm{~mL} / \mathrm{min}$ using water and $\mathrm{MeCN}$ as mobile phases (both $+0.1 \% \mathrm{FA}$ ). The elution program consisted of $8 \% \mathrm{MeCN}$ for $8 \mathrm{~min}, 8-60 \% \mathrm{MeCN}$ over $18 \mathrm{~min}$, and $60-100 \% \mathrm{MeCN}$ over 5 min. A broad peak composed of GggA substrate and product was collected between 22-25 min. The ${ }^{13} \mathrm{C}_{3}-\mathrm{A} 28-\mathrm{GggA}$ reaction was purified by semi-preparative HPLC using a Phenomenex Luna C18(2) $100 \AA$ column $(5 \mu \mathrm{m}, 250 \times 10 \mathrm{~mm})$ operating at $2.5 \mathrm{~mL} / \mathrm{min}$ using water and $\mathrm{MeCN}$ as mobile phases, both containing $0.1 \% \mathrm{FA}$. Elution was carried out with the following program: $8 \% \mathrm{MeCN}$ for $5 \mathrm{~min}, 8-60 \% \mathrm{MeCN}$ over $15 \mathrm{~min}$, and $60-100 \% \mathrm{MeCN}$ over $5 \mathrm{~min}$. Substrate and product co-eluted between 19-20 min.

\section{Analytical-Scale Co-Expression of GggB and 6HMBPGggA Fusion Proteins}

The relevant pRSFDuet-1_6HMBPgggA_gggB vector, along with pDB1282 (isc operon), was transformed into $E$. coli BL21(DE3) by heat-shock and plated onto LB agar supplemented 
with $100 \mu \mathrm{g} / \mathrm{mL}$ ampicillin (Amp) and $50 \mu \mathrm{g} / \mathrm{mL}$ kanamycin (Kan). A $15 \mathrm{~mL}$ culture tube containing $5 \mathrm{~mL}$ LB (+50 $\mu \mathrm{g} / \mathrm{mL}$ Kan and $100 \mu \mathrm{g} / \mathrm{mL}$ Amp) was inoculated with a single colony and grown overnight at $37^{\circ} \mathrm{C} / 200 \mathrm{rpm}$. The following morning, $0.5 \mathrm{~mL}$ of overnight culture was used to inoculate a $125 \mathrm{~mL}$ flask containing $50 \mathrm{~mL}$ Terrific Broth (Kan/Amp). This $50 \mathrm{~mL}$ culture was grown at $37^{\circ} \mathrm{C} / 200 \mathrm{rpm}$ to an optical density (at $600 \mathrm{~nm}, \mathrm{OD}_{600}$ ) of 0.4 , at which point it was supplemented with $0.05 \mathrm{mM} \mathrm{FeCl}_{3}$ and $0.05 \%$ arabinose to induce expression of the isc operon. The culture was then grown to $\mathrm{OD}_{600} \approx 0.8$ at which point it was supplemented with $0.5 \mathrm{mM}$ IPTG to induce co-expression of $6 \mathrm{HMBPGggA}$ and $\mathrm{GggB}$. Growth was continued at $37^{\circ} \mathrm{C} / 200$ rpm for 18 hours. Cells were harvested by centrifugation $\left(30,000 \mathrm{~g}, 30 \mathrm{~min}, 4^{\circ} \mathrm{C}\right)$. A typical yield was $100-200 \mathrm{mg}$ cell paste per $50 \mathrm{~mL}$ culture.

\section{Analytical-Scale Purification and Protease Cleavage of 6HMBPGggA Fusion Proteins}

Cell paste was resuspended in lysis buffer $(1 \mathrm{~mL} / 200 \mathrm{mg}$ cell paste), which consisted of $50 \mathrm{mM} \mathrm{Na} 2 \mathrm{PO}_{4}, 300 \mathrm{mM} \mathrm{NaCl}, 10 \mathrm{mM}$ imidazole, $\mathrm{pH} 8$ (NPi-10) containing 10\% (v/v) BugBuster 10x Protein Extraction Reagent. Benzonase-Nuclease $(25 \mathrm{U} / \mu \mathrm{L})$ and Protease Inhibitor Cocktail (Sigma) were added at $1 \mu \mathrm{L} / \mathrm{mL}$ and $10 \mu \mathrm{L} / \mathrm{mL}$, respectively. The suspension was incubated on ice on a rocking platform for $30 \mathrm{~min}$. Crude cell lysate was centrifuged to remove cell debris. Clarified lysate was loaded onto a HisPur Ni-NTA Spin Column $(0.2 \mathrm{~mL}$ resin bed volume, Thermo-Fisher), which had been equilibrated with NPi-10. Spin purification was carried out as per instructions. Briefly, once loaded, the resin was washed with 5 resin bed volumes of NPi-10 followed by 5 volumes of wash buffer consisting of $50 \mathrm{mM} \mathrm{Na}{ }_{2} \mathrm{PO}_{4}, 300 \mathrm{mM} \mathrm{NaCl}, 20 \mathrm{mM}$ imidazole, $\mathrm{pH} 8$ (NPi-20). 6HMBPGggA was eluted from the resin using 2-4 volumes of elution buffer consisting of $50 \mathrm{mM} \mathrm{Na}_{2} \mathrm{PO}_{4}, 300 \mathrm{mM} \mathrm{NaCl}, 500 \mathrm{mM}$ imidazole, pH 8 (NPi-500). Centrifugation for all steps was carried out at $700 \mathrm{~g}$ for 2 min. Protein elution was monitored by Bradford Reagent. Isolated 6HMBPGggA was exchanged into cleavage buffer $(50 \mathrm{mM} \mathrm{Tris-HCl}$, $150 \mathrm{mM} \mathrm{NaCl}, \mathrm{pH}$ 8) or water using a PD-10 desalting column (GE Healthcare) following manufacturer's instructions.

Once isolated, the 6HMBPGggA fusion proteins were proteolyzed to facilitate analysis by HPLC-Qtof-MS. First, the fusion protein was treated with HRV3C protease to remove the $6 \mathrm{HMBP}$ tag. Next, the liberated HRV3C-cleaved GggA peptide was further truncated using AspN. All protease reactions were performed in cleavage buffer composed of $50 \mathrm{mM}$ Tris $\mathrm{HCl}$, $150 \mathrm{mM} \mathrm{NaCl}, \mathrm{pH}$ 8. For AspN treatment, the buffer was supplemented with $\mathrm{ZnSO}_{4}$ at a final concentration of $2 \mathrm{mM}$. Proteolyzed samples were then analyzed by HPLC-Qtof-MS using the Phenomenex Jupiter C18 300A column and gradient detailed above (in General Procedures).

\section{Identification of Streptosactin}

S. thermophilus JIM 8232 was cultured as described previously using a chemically defined medium (CDM) optimized for streptococcal growth. ${ }^{3,4}$ Briefly, $5 \mathrm{~mL}$ of Brain Heart Infusion medium in a $14 \mathrm{~mL}$ culture tube was inoculated with $S$. thermophilus JIM 8232 and grown at $42^{\circ} \mathrm{C}$ overnight without shaking. These were then spun down, washed with CDM once, and used to inoculate $225 \mathrm{~mL}$ CDM in $250 \mathrm{~mL}$ bottles. The bottles were capped and grown standing at $42^{\circ} \mathrm{C}$ for $18 \mathrm{~h}$. Then, the supernatant was isolated by filtration and subjected to solidphase extraction with $1 \mathrm{~g}$ of $\mathrm{C} 18$ resin, which had been washed with $\mathrm{MeOH}$ and equilibrated with water $(+0.1 \% \mathrm{FA})$. After application of the supernatant, the resin was washed with $5 \mathrm{~mL}$ of $0.1 \%$ FA solution, and elution was carried out with $5 \mathrm{~mL}$ passages of $20 \%, 40 \%$, and $100 \%$ $\mathrm{MeOH}$ (in water). The eluates were dried in vacuo and resuspended in $\sim 0.5 \mathrm{~mL}$ of $0.1 \% \mathrm{FA}$ solution for HPLC-MS analysis. The large-scale growths used the same culture procedure with 
18 culture bottles totaling $\sim 4 \mathrm{~L}$ of culture. This was passed through $\sim 5 \mathrm{~g}$ of washed and equilibrated $\mathrm{C} 18$ resin, and $10 \mathrm{~mL}$ elutions were collected as above. Dried extracts from these cultures were resuspended in $\sim 4 \mathrm{~mL}$ of $0.1 \%$ FA.

For a timecourse of streptosactin production, S. thermophilus JIM 8232 was cultured in two $250 \mathrm{~mL}$ culture bottles each containing $225 \mathrm{~mL}$ of CDM media as described above. Aliquots of $25 \mathrm{~mL}$ were collected from each culture at $4,8,12,15,24,32,48,72$, and $96 \mathrm{~h}$ after inoculation. Aliquoted culture supernatants were then passed through washed and equilibrated $0.5 \mathrm{~g}$ Oasis HLB solid phase extraction cartridges. The cartridges were then washed with $5 \mathrm{~mL}$ of $0.1 \%$ FA solution, and elution carried out with $5 \mathrm{~mL}$ of $100 \% \mathrm{MeOH}$. All extracts were dried in vacuo, resuspended in $200 \mu \mathrm{L}$ of $0.1 \%$ FA solution, then characterized by HPLC-Qtof-MS.

HPLC-Qtof-MS utilized a Phenomenex Omega Polar C18 column (5 $\mu \mathrm{m}, 2.1$ x $150 \mathrm{~mm})$ with water and $\mathrm{MeCN}$ (both $+0.1 \% \mathrm{FA}$ ) as mobile phase. The extracts were analyzed with the following method: 3.5 min $100 \%$ water, $0-100 \%$ MeCN over $16.5 \mathrm{~min}$. An optimized method was developed as well: 3.5 min 100\% water, 0-20\% MeCN over $11.5 \mathrm{~min}, 20-100 \%$ MeCN over 5 min. Under these conditions, streptosactin eluted at 8.9 min. Synthetic streptosactin (see below) was analyzed with the exact same method as were 1:1 mixtures of authentic and synthetic streptosactin.

To analyze the HPLC-Qtof-MS data, molecular formulae were first generated for all possible products of the ggg locus based on the available information from in vitro studies. This library of formulae was then input into the Agilent MassHunter software "Find Compounds by Formula" feature, which searched for possible matches in the supernatants of $S$. thermophilus JIM 8232. These matches were then selected for MS/MS fragmentation, and resultant spectra were inspected for fragment ions consistent with the peptide sequence of the candidate streptosactin product. The $S$. thermophilus supernatant showed a match only to one of the candidates from this list, a low-abundance ion that yielded MS/MS fragment ions consistent with a 14 mer bicyclic product. This lead was then partially purified from $\sim 1 \mathrm{~L}$ of $S$. thermophilus JIM 8232 cultures, prepared as described above. At higher concentrations, the MS/MS fragmentation spectra of this lead were perfectly consistent with the 14 mer synthetic streptosactin (see below). The authentic and synthetic material were additionally shown to coelute when mixed and analyzed by HPLC-Qtof-MS as described above. This work confirmed the structure of streptosactin from S. thermophilus JIM 8232 to be a 14mer peptide with the

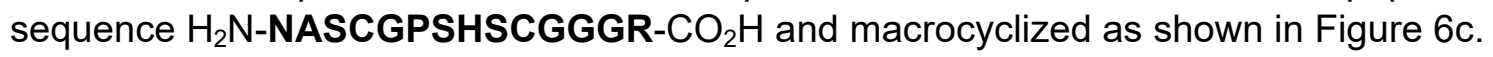

\section{Large-Scale Co-Expression of GggB and 6HMBPGggA-R22 for Synthetic Streptosactin}

The E. coli BL21(DE3) strain containing pRSFDuet-1_6HMBPgggA-R22_gggB and pDB1282 were streaked out from glycerol stock onto an LB agar plate supplemented with Kan $(50 \mu \mathrm{g} / \mathrm{mL})$ and Amp $(100 \mu \mathrm{g} / \mathrm{mL})$ and incubated at $37^{\circ} \mathrm{C}$ overnight. A single colony was then used to inoculate either a $250 \mathrm{~mL}$ flask containing $100 \mathrm{~mL} \mathrm{LB}(+50 \mu \mathrm{g} / \mathrm{mL} \mathrm{Kan}$ and $100 \mu \mathrm{g} / \mathrm{mL}$ Amp) or a $125 \mathrm{~mL}$ flask containing $50 \mathrm{~mL} \mathrm{LB}$, which was then grown overnight at $37^{\circ} \mathrm{C} / 200 \mathrm{rpm}$. This seed culture was then used to inoculate $1.6 \mathrm{~L}$ TB in a $4 \mathrm{~L}$ flask or $0.8 \mathrm{~L}$ TB in a $2 \mathrm{~L}$ flask at $1 \%$ dilution. Expression cultures were grown continuously at $37^{\circ} / 200 \mathrm{rpm}$. Arabinose and $\mathrm{FeCl}_{3}$ were added to the culture at $\mathrm{OD}_{600} \approx 0.4$ at final concentrations of $0.05 \%$ and $0.05 \mathrm{mM}$, respectively. IPTG was added to the culture at $\mathrm{OD}_{600} \approx 0.8$ at a final concentration of $0.5 \mathrm{mM}$. Following $18 \mathrm{~h}$ of growth post-induction with IPTG, cells were harvested by centrifugation $\left(15,000 \times \mathrm{g}, 30 \mathrm{~min}, 4^{\circ} \mathrm{C}\right)$ and frozen at $-80^{\circ} \mathrm{C}$. A typical yield was $4.5-6.5 \mathrm{~g}$ cell paste per $\mathrm{L}$ culture. Several rounds of expression were carried out, totaling $25.6 \mathrm{~L}$ culture and amounting to $134 \mathrm{~g}$ cell paste before purification. 


\section{Large-Scale Purification and Protease Cleavage of 6HMBPGggA-R22}

Thawed cell paste from the step above was resuspended in NPi-10 (5 mL/g) and supplemented with Benzonase-Nuclease $(0.1 \mu \mathrm{L} / \mathrm{mL})$, SIGMAFAST Protease Inhibitor Tablet (1 tablet per $100 \mathrm{~mL})$, and lysozyme $(1 \mathrm{mg} / \mathrm{mL})$. The suspension was stirred for $\sim 45 \mathrm{~min}$ and then subjected to 3 rounds of $4 \mathrm{~min}$ of sonication, $15 \mathrm{sec}$ on/15 sec off, $30 \%$ amplitude. During sonication, cells were placed in an ice bath and allowed to rest on ice for several min between rounds. Cell debris was removed by centrifugation $\left(33,000 \mathrm{~g}, 65 \mathrm{~min}, 4{ }^{\circ} \mathrm{C}\right)$, and the cleared lysate loaded onto a hand-poured $\mathrm{Ni}$ column ( $1 \mathrm{~mL}$ resin per $30 \mathrm{~mL}$ lysate), which had been equilibrated with $10 \mathrm{CV}$ of NPi-10. Next, the column was washed with $5 \mathrm{CV}$ of NPi-10 followed by $5 \mathrm{CV}$ of NPi-20. Finally, 6HMBPGggA-R22 was eluted from the column with $10 \mathrm{CV}$ of NPi500 . The elution was then concentrated $\sim 5 x$ using an Amicon Ultra Centrifugal Filter (Membrane NMWL, $30 \mathrm{kDa}$ ) and exchanged into cleavage buffer by gel filtration using Sephadex G-25 resin. The 6HMBPGggA-R22 solution collected off the G-25 column was then supplemented with HRV3C Protease $(10 \mathrm{U} / \mathrm{mL})$ and incubated at $4^{\circ} \mathrm{C}$ for $16 \mathrm{~h}$. Following cleavage with HRV3C protease, the sample was clarified by centrifugation to remove precipitant. The solution was then supplemented with $\mathrm{ZnSO}_{4}$ at a final concentration of $2 \mathrm{mM}$ and AspN (100 ng per $1 \mathrm{~mL}$ ) and incubated at $37^{\circ} \mathrm{C}$ for $16 \mathrm{~h}$.

\section{Purification of the AspN Cleaved GggA-R22 21mer}

The AspN reaction mixture from above was heat-quenched at $95^{\circ} \mathrm{C}$ and clarified by centrifugation and filtration through a $0.22 \mu \mathrm{m}$ syringe filter. The desired C-terminal $21 \mathrm{mer}$ fragment was isolated by HPLC purification using a semi-preparative Phenomenex Jupiter $300 \AA$ C18 column $(5 \mu \mathrm{m}, 10 \times 250 \mathrm{~mm})$ operating at $2.5 \mathrm{~mL} / \mathrm{min}$. The mobile phase consisted of water and $\mathrm{MeCN}$, both supplemented with $0.1 \% \mathrm{FA}$. The mixture (900 $\mu \mathrm{L}$ per injection) was resolved with the following method: $8 \%$ MeCN for 5 min, 8-52\% MeCN over 11 min, $52-100 \%$ MeCN over $4 \mathrm{~min}, 100 \%$ for $7 \mathrm{~min}$. The peak corresponding to the desired $21 \mathrm{mer}$, which eluted at $\sim 46-48 \%$ $\mathrm{MeCN}$, was collected, rotavaped to remove $\mathrm{MeCN}$ and then lyophilized to remove residual water.

\section{Trypsin Cleavage of the AspN Cleaved GggA-R22 21mer to Give Streptosactin and Purification of Streptosactin}

Lyophilized $21 \mathrm{mer}$ from above was resuspended in cleavage buffer $(1 \mathrm{~mL}$ per $\sim 5 \mathrm{mg}$ peptide) and supplemented with $\mathrm{CaCl}_{2}$ at a final concentration of $20 \mathrm{mM}$ and trypsin (200 $\mathrm{ng}$ per $1 \mathrm{~mL}$ ). The cleavage reaction was incubated at $37^{\circ} \mathrm{C}$ for $16 \mathrm{~h}$ and then resolved by HPLC

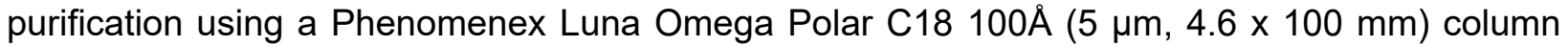
operating at $0.75 \mathrm{~mL} / \mathrm{min}$ with the following method: $100 \%$ water for $5 \mathrm{~min}, 0-20 \% \mathrm{MeCN}$ over $10 \mathrm{~min}, 20-100 \% \mathrm{MeCN}$ over $3 \mathrm{~min}$, and 100\% MeCN for $6 \mathrm{~min}$. Streptosactin eluted at 12-13\% $\mathrm{MeCN}$ and was dried by lyophilization. The identity of the purified product was confirmed by HPLC-Qtof-MS and NMR (Figure S8).

\section{Bioactivity of Streptosactin}

Bacterial strains tested with streptosactin are listed in Table S26. L. lactis, E. faecalis, and other streptococcal strains listed were routinely grown on Todd-Hewitt plates (TH) with $1.4 \%$ Bacto-Agar and $0.2 \%$ yeast extract (all BD Biosciences), TH broth with $0.2 \%$ yeast (THY), or in Federle chemically-defined medium (FCDM) plus $1 \%$ glucose at $37^{\circ} \mathrm{C}$ in an atmosphere of $5 \% \mathrm{CO}_{2}$. The components and recipe for FCDM used were as described previously. ${ }^{5}$ 
To monitor the effect of streptosactin, prestored glycerol stocks of bacterial strains were inoculated into $\mathrm{THY}$ broth and incubated overnight at $37^{\circ} \mathrm{C}$ in an atmosphere of $5 \% \mathrm{CO}_{2} . \mathrm{FCDM}$ was prepared and prewarmed at $37^{\circ} \mathrm{C}$ in an atmosphere of $5 \% \quad \mathrm{CO}_{2}$ overnight. The next morning, strains were transferred to sterile tubes and centrifuged at room temperature at $4000 \mathrm{~g}$ for $10 \mathrm{~min}$. Strains were resuspended in $1 \mathrm{~mL}$ prewarmed FCDM, transferred to microcentrifuge tubes and centrifuged again at room temperature at $14,000 \mathrm{~g}$ for $5 \mathrm{~min}$. Supernatant was discarded and strains were resuspended in $1 \mathrm{~mL}$ fresh prewarmed FCDM. Resuspended strains were then inoculated into $6 \mathrm{~mL}$ prewarmed FCDM at 1:200 dilution. If required, at 1 hour postinoculation $100 \mathrm{nM}$ or $1 \mu \mathrm{M}$ streptosactin was added. Growth was monitored approximately every 45 min to 1 hour, and at each time point strains were monitored by measuring $\mathrm{OD}_{600}$ with an GENESYS 30 UV-visible spectrophotometer (Thermo-Fisher). The resulting data were plotted using Graph Pad Prism 8.0.0 (GraphPad Software).

\section{Autoaggregation Assay with Streptosactin}

Autoaggregation assays were carried out in 96-well plate standing cultures. $S$. thermophilus JIM 8232 was streaked out from a frozen glycerol stock onto a THY agar plate and incubated overnight at $37^{\circ} \mathrm{C}$ under $5 \% \mathrm{CO}_{2}$ atmosphere. Multiple colonies from the plate were directly suspended in liquid CDM. The bacterial suspension was then diluted with CDM to an initial $\mathrm{OD}_{600}$ of 0.05 and dispensed into a 96-well plate. Streptosactin was dissolved in $\mathrm{H}_{2} \mathrm{O}$ (1.28 $\mathrm{mg} / \mathrm{mL}$ ) and then diluted 10-fold in CDM. The stock was used to set up an eight-step 2-fold serial dilution series across each of two row, starting with $64 \mu \mathrm{g} / \mathrm{mL}$ streptosactin to $0.5 \mu \mathrm{g} / \mathrm{mL}$. The four remaining wells in each row served as the vehicle control (no streptosactin). The total volume was $100 \mu \mathrm{L}$ in each well. The plate was then incubated at $37^{\circ} \mathrm{C}, 5 \% \mathrm{CO}_{2}$ for $20 \mathrm{~h}$. Images were then collected after $20 \mathrm{~h}$. All liquid CDM was prewarmed in the $37^{\circ} \mathrm{C}, 5 \% \mathrm{CO}_{2}$ incubator prior to use. 


\section{DNA and Amino Acid Sequences}

6xHis-MBP (with Poly-Linker and HRV-3C Protease Cleavage Site):

Amino acid sequence:

MGSSHHHHHHSSGMKIEEGKLVIWINGDKGYNGLAEVGKKFEKDTGIKVTVEHPDKLEEKFPQ VAATGDGPDIIFWAHDRFGGYAQSGLLAEITPDKAFQDKLYPFTWDAVRYNGKLIAYPIAVEALS LIYNKDLLPNPPKTWEEIPALDKELKAKGKSALMFNLQEPYFTWPLIAADGGYAFKYENGKYDIK DVGVDNAGAKAGLTFLVDLIKNKHMNADTDYSIAEAAFNKGETAMTINGPWAWSNIDTSKVNY GVTVLPTFKGQPSKPFVGVLSAGINAASPNKELAKEFLENYLLTDEGLEAVNKDKPLGAVALKS YEEELAKDPRIAATMENAQKGEIMPNIPQMSAFWYAVRTAVINAASGRQTVDEALKDAQTNSS SNNNNNNNNNNLGLEVLFQGPEFGS

DNA sequence:

ATGGGTTCTAGCCACCACCACCACCACCACTCTAGCGGTATGAAAATTGAAGAAGGCAAAC TGGTTATTTGGATCAATGGCGATAAAGGCTATAATGGTCTGGCAGAAGTTGGCAAAAAATT CGAAAAAGATACCGGCATTAAAGTGACCGTTGAACATCCGGATAAACTGGAAGAAAAATTT CCGCAGGTTGCAGCAACCGGTGATGGTCCGGATATTATCTTTTGGGCACATGATCGTTTTG GTGGTTATGCACAGAGCGGTCTGCTGGCAGAAATTACACCGGATAAAGCATTTCAGGACAA ACTGTATCCGTTTACCTGGGATGCAGTTCGCTATAACGGTAAACTGATTGCATATCCGATTG CAGTTGAAGCACTGAGCCTGATCTATAACAAAGATCTGCTGCCGAATCCGCCTAAAACCTG GGAAGAAATTCCGGCACTGGATAAAGAACTGAAAGCAAAAGGTAAAAGCGCACTGATGTTT AATCTGCAAGAACCGTATTTTACCTGGCCTCTGATTGCAGCAGATGGTGGCTATGCATTCA AATATGAAAACGGCAAATATGATATCAAAGACGTGGGTGTTGATAATGCGGGTGCAAAAGC CGGTCTGACCTTTCTGGTTGATCTGATTAAAAACAAACACATGAACGCCGATACCGATTATA GCATTGCAGAAGCAGCATTTAACAAAGGTGAAACCGCAATGACAATTAATGGTCCGTGGGC ATGGTCAAATATTGATACCAGCAAAGTGAATTATGGTGTTACCGTTCTGCCGACATTTAAAG GTCAGCCGAGCAAACCGTTTGTTGGTGTTCTGAGCGCAGGTATTAATGCAGCAAGCCCGA ACAAAGAACTGGCAAAAGAATTTCTGGAAAACTATCTGCTGACCGATGAAGGTCTGGAAGC AGTGAATAAAGATAAACCGCTGGGTGCAGTTGCACTGAAAAGCTATGAAGAGGAACTGGC CAAAGATCCGCGTATTGCAGCAACAATGGAAAATGCACAGAAAGGCGAAATTATGCCGAAT ATTCCGCAGATGAGCGCATTTTGGTATGCCGTTCGTACCGCAGTGATTAATGCCGCATCAG GTCGTCAGACCGTTGATGAAGCCCTGAAAGATGCCCAGACCAATAGCAGCAGCAATAACA ATAATAACAACAACAATAACAATCTGGGCCTGGAAGTTCTGTTTCAGGGTCCGGAATTCGG ATCC

GggA (S. thermophilus JIM 8232):

Amino Acid Sequence:

MEKLQVIDLEELLEFDQGYVINASCGPSHSCGGGR-

DNA Sequence (native):

ATGGAAAAACTTCAGGTGATTGACCTTGAAGAACTTTTAGAGTTTGATCAAGGGTATGTAAT

TAATGCTAGCTGTGGTCCAAGTCATTCTTGTGGCGGTGGTCGATAG

DNA Sequence (codon-optimized for E. coli):

ATGGAGAAACTTCAGGTCATTGATTTAGAGGAATTGCTTGAGTTTGACCAAGGATACGTCAT CAACGCTTCATGTGGACCGTCGCACTCTTGTGGAGGAGGACGCTAA

GggA-1xSCGGGR:

Amino acid sequence:

MEKLQVIDLEELLEFDQGYVINASCGGGR- 
DNA sequence (codon-optimized for E. coli):

ATGGAGAAACTTCAGGTCATTGATTTAGAGGAATTGCTTGAGTTTGACCAAGGATACGTCAT CAACGCTTCATGTGGAGGCGGCCGCTAA

GggA-2xSCGGGR:

Amino acid sequence:

MEKLQVIDLEELLEFDQGYVINASCGGGRSCGGGR-

$D N A$ sequence (codon-optimized for $E$. coli):

ATGGAGAAACTTCAGGTCATTGATTTAGAGGAATTGCTTGAGTTTGACCAAGGATACGTCAT

CAACGCTTCATGTGGAGGCGGCCGCAGCTGCGGCGGTGGTCGCTAA

GggA-3xSCGGGR:

Amino acid sequence:

MEKLQVIDLEELLEFDQGYVINASCGGGRSCGGGRSCGGGR-

$D N A$ sequence (codon-optimized for $E$. coli):

ATGGAGAAACTTCAGGTCATTGATTTAGAGGAATTGCTTGAGTTTGACCAAGGATACGTCAT CAACGCTTCATGTGGAGGCGGCCGCAGCTGCGGCGGTGGTCGCAGCTGCGGTGGTGGC CGCTAA

GggA-3xSCGGGR, C31S:

Amino acid sequence

MEKLQVIDLEELLEFDQGYVINASCGGGRSSGGGRSCGGGR-

$D N A$ sequence (codon-optimized for E. coli)

ATGGAGAAACTTCAGGTCATTGATTTAGAGGAATTGCTTGAGTTTGACCAAGGATACGTCAT CAACGCTTCATGTGGAGGCGGCCGCAGCTCCGGCGGTGGTCGCAGCTGCGGTGGTGGC CGCTAA

GggA-4xSCGGGR:

Amino acid sequence:

MEKLQVIDLEELLEFDQGYVINASCGGGRSCGGGRSCGGGRSCGGGR-

$D N A$ sequence (codon-optimized for $E$. coli):

ATGGAGAAACTTCAGGTCATTGATTTAGAGGAATTGCTTGAGTTTGACCAAGGATACGTCAT CAACGCTTCATGTGGAGGCGGACGGAGCTGCGGCGGTGGTCGCAGCTGCGGTGGTGGC CGCAGCTGCGGCGGCGGCCGCTAA

GggA-R22:

Amino acid sequence:

MEKLQVIDLEELLEFDQGYVIRNASCGPSHSCGGGR-

DNA sequence (codon-optimized for E. coli):

ATGGAGAAACTTCAGGTCATTGATTTAGAGGAATTGCTTGAGTTTGACCAAGGATACGTCAT CAGGAACGCTTCATGTGGACCGTCGCACTCTTGTGGAGGAGGACGCTAA

GggB wildtype (S. thermophilus JIM 8232):

Amino acid sequence:

MIKTIETDIGTYYFDSVNFTLSLSPISKQSSPTLDSVEDGVLKKVVINISNSCNLSCSYCYADGGN YGMDNRIMDLTTADNIIQEIASKGVTQINRLILFGGEPFLNIELFIYFIEKLSTLLNVVKIETVTNGTV LNKRVKEMLVKFHPYLTISLDGPEIVHDRLRGRGSHRKTLRFINYLKNIDYENFEIASTYTRLHQK 
NGLSREDIFQYFTDMDVHFNINDVFTKNKVLIVKEMEKSLAERKQFIDKSIQHVINNNEKAFISPIL YDVLISMIYKSTNRTFCDDIDPSNTLTYDVDGSKKLCFRFWGTHNSPKAESFNNKDNFEKCKNC WCRGMCLECVANVIDGYSSVISEDGEFLECSKPELMEYCIKQIIYLSKDREKLSRLVNNFRGFIR YA-

DNA sequence (native):

ATGATAAAGACAATAGAAACAGATATAGGAACATATTATTTTGATTCTGTTAATTTTACTTTAT CTTTGTCACCTATTTCAAAACAAAGTTCACCAACTCTAGATTCTGTTGAAGATGGTGTATTAA AAAAAGTAGTTATAAATATTTCTAATAGTTGTAATTTATCTTGTTCGTATTGTTATGCAGATG GTGGTAACTATGGTATGGATAATCGTATTATGGATTTAACTACTGCTGATAATATTATCCAA GAGATAGCAAGTAAAGGAGTTACACAAATCAACCGTCTCATACTTTTCGGGGGAGAACCTT TTTTAAATATAGAATTATTTATATATTTTATAGAAAAATTATCTACATTATTAAATGTAGTGAAA ATTGAAACAGTTACTAATGGTACTGTTTTAAATAAGCGTGTTAAAGAAATGCTTGTTAAATTT CATCCTTATTTAACCATAAGTTTAGATGGACCAGAAATTGTTCATGATAGACTCAGAGGAAG AGGGAGCCATCGAAAAACATTACGTTTTATTAATTATTTAAAGAATATTGATTATGAAAATTT TGAAATAGCCTCGACATATACTAGACTTCATCAAAAAAATGGTCTAAGTAGAGAAGATATCT TTCAATATTTTACTGATATGGATGTGCATTTTAATATAAATGATGTTTTTACTAAAAATAAAGT GCTAATTGTGAAAGAAATGGAAAAAAGTTTGGCTGAAAGAAAACAGTTCATAGATAAATCCA TTCAACATGTAATCAACAACAATGAGAAGGCATTTATCAGTCCTATTTTATATGATGTATTAA TATCAATGATATACAAGAGTACGAATCGTACATTTTGTGATGATATTGACCCTTCGAATACAT TAACTTATGATGTAGATGGTAGTAAGAAACTATGTTTCAGATTTTGGGGAACTCACAACAGT CCTAAAGCGGAATCATTTAACAACAAAGATAACTTTGAAAAGTGTAAAAACTGCTGGTGTAG AGGTATGTGCTTGGAATGCGTTGCCAATGTTATTGATGGATATTCTTCTGTAATTAGTGAAG ATGGGGAATTTCTTGAATGCTCTAAACCAGAACTGATGGAATACTGTATTAAACAGATTATA TATTTATCCAAGGACAGAGAAAAATTATCTAGGTTGGTAAATAATTTTAGGGGGTTTATACG CTATGCTTAG

DNA sequence (codon-optimized for $E$. coli):

ATGATAAAGACCATCGAGACTGACATCGGAACATATTACTTCGATAGCGTCAACTTTACCCT TAGCCTTTCACCGATTTCTAAACAGAGTTCACCAACATTAGACTCAGTGGAAGATGGGGTC TTGAAAAAAGTAGTGATAAACATATCAAACTCGTGTAACTTGTCGTGTTCTTACTGCTATGC CGACGGTGGCAACTACGGCATGGACAACCGCATAATGGACTTGACGACTGCGGACAATAT CATCCAAGAGATCGCAAGTAAGGGTGTGACCCAGATCAACCGTCTGATTTTGTTTGGAGGA GAGCCCTTCTTAAATATTGAACTGTTTATCTACTTTATCGAGAAGTTGAGCACGCTTCTGAA CGTAGTGAAGATAGAAACTGTGACTAACGGGACAGTACTTAACAAGCGTGTCAAAGAAATG CTTGTTAAGTTTCATCCCTACTTAACAATTTCGCTTGACGGACCCGAAATAGTGCATGATAG ATTACGCGGACGCGGCAGCCATCGTAAGACTTTGCGGTTCATTAACTACCTTAAGAATATA GATTATGAAAACTTCGAAATAGCGTCTACATATACCCGGTTACATCAAAAAAACGGATTGAG TCGTGAGGACATTTTTCAATATTTTACGGATATGGACGTCCACTTCAATATAAACGATGTTTT TACCAAAAATAAGGTACTTATAGTTAAGGAGATGGAAAAAAGCCTTGCTGAGCGGAAGCAG TTCATCGATAAGTCAATACAACATGTCATCAATAATAACGAAAAAGCGTTTATCAGCCCGAT CTTGTATGACGTTTTAATTTCCATGATTTACAAATCCACTAACCGGACGTTCTGTGACGACA TCGACCCGAGTAATACATTAACCTATGACGTGGATGGCAGCAAGAAACTTTGTTTCCGGTT CTGGGGCACTCACAACAGCCCGAAAGCGGAATCTTTTAATAACAAAGACAACTTTGAGAAG TGCAAAAATTGTTGGTGTCGGGGTATGTGTCTTGAATGTGTTGCAAATGTCATAGATGGCT ATAGTAGTGTCATTTCTGAAGATGGCGAATTCTTAGAGTGCAGCAAACCCGAATTAATGGA ATATTGTATTAAGCAAATAATTTACCTGTCTAAAGACCGGGAGAAATTATCGCGTTTAGTTAA CAACTTTCGGGGTTTTATCCGTTATGCTTAG 
Table S1. Plasmids used and generated in this study.

\begin{tabular}{c|c|c}
\hline Plasmid & Purpose & Source \\
\hline pET-28b(+) & Kan $^{\mathrm{R}}$, Expression vector & Novagen \\
\hline pET-28b(+)_gggB & Expression of GggB & This study \\
\hline pDB1282 & Amp $^{\mathrm{R}}$, isc operon & $\begin{array}{c}\text { Prof. Dennis } \\
\text { Dean }\end{array}$ \\
\hline pRSFDuet-1 & Kan $^{\mathrm{R}}$, Co-expression vector & Novagen \\
\hline pBAD_6HMBPP_HTFLAG & Source of 6HMBP tag & Mo Lab \\
\hline pRSFDuet-1_6HMBPgggA_gggB & $\begin{array}{c}\text { Co-expression of 6HMBPGggA and } \\
\text { GggB }\end{array}$ & This study \\
\hline pRSFDuet-1_6HMBPgggA-1x_gggB & $\begin{array}{c}\text { Co-expression of 6HMBPGggA-1x } \\
\text { and GggB }\end{array}$ & This study \\
\hline pRSFDuet-1_6HMBPgggA-2x_gggB & $\begin{array}{c}\text { Co-expression of 6HMBPGggA-2x } \\
\text { and GggB }\end{array}$ & This study \\
\hline pRSFDuet-1_6HMBPgggA-3x,C31S_gggB & $\begin{array}{c}\text { Co-expression of 6HMBPGggA- } \\
\text { x3,C31S and GggB }\end{array}$ & This study \\
\hline pRSFDuet-1_6HMBPgggA-4x_gggB & $\begin{array}{c}\text { Co-expression of 6HMBPGggA-x4 } \\
\text { and GggB }\end{array}$ & This study \\
\hline pRSFDuet-1_6HMBPgggA-R22_gggB & $\begin{array}{c}\text { Co-expression of 6HMBPGggA-R22 } \\
\text { and GggB }\end{array}$ & This study \\
\hline
\end{tabular}


Table S2. S. thermophilus JIM 8232 and E. coli strains used or generated in this study.

\begin{tabular}{|c|c|c|}
\hline Strain & Purpose & Source \\
\hline S. thermophilus JIM 8232 & Characterize ggg locus & $\begin{array}{l}\text { Dr. Christine } \\
\text { Delorme }\end{array}$ \\
\hline E. coli DH5a & Host strain for cloning & NEB \\
\hline E. coli BL21(DE3) & Host strain for expression & NEB \\
\hline $\begin{array}{l}\text { E. coli BL21(DE3)+ } \\
\text { pET-28b }(+) \_g g g B\end{array}$ & Expression of GggB & This study \\
\hline $\begin{array}{c}\text { E. coli BL21(DE3) + } \\
\text { pRSFDuet-1_6HMBPgggA_gggB + } \\
\text { pDB1282 }\end{array}$ & $\begin{array}{l}\text { Co-expression of } 6 \mathrm{HMBPGggA} \text { and } \\
\text { GggB }\end{array}$ & This study \\
\hline $\begin{array}{c}\text { E. coli BL21(DE3) + } \\
\text { pRSFDuet-1_6HMBPgggA-1x_gggB + } \\
\text { pDB1282 }\end{array}$ & $\begin{array}{l}\text { Co-expression of } 6 \mathrm{HMBPGggA}-\mathrm{x} 1 \\
\text { and } \mathrm{GggB}\end{array}$ & This study \\
\hline $\begin{array}{c}\text { E. coli BL21(DE3) + } \\
\text { pRSFDuet-1_6HMBPgggA-2x_gggB + } \\
\text { pDB1282 }\end{array}$ & $\begin{array}{c}\text { Co-expression of } 6 \mathrm{HMBPGggA}-\mathrm{x} 2 \\
\text { and GggB }\end{array}$ & This study \\
\hline $\begin{array}{c}\text { E. coli BL21(DE3) + } \\
\text { pRSFDuet-1_6HMBPgggA-3x_gggB + } \\
\text { pDB1282 }\end{array}$ & $\begin{array}{l}\text { Co-expression of } 6 \mathrm{HMBPGggA}-\mathrm{x} 3 \\
\text { and } \mathrm{GggB}\end{array}$ & This study \\
\hline $\begin{array}{c}\text { E. coli BL21(DE3) + } \\
\text { pRSFDuet-1_6HMBPgggA-3x,C31S_gggB } \\
\text { pDB1282 }\end{array}$ & $\begin{array}{c}\text { Co-expression of } 6 \mathrm{HMBPGggA}- \\
\times 3, \mathrm{C} 31 \mathrm{~S} \text { and GggB }\end{array}$ & This study \\
\hline $\begin{array}{c}\text { E. coli BL21(DE3) + } \\
\text { pRSFDuet-1_6HMBPgggA-4x_gggB + } \\
\text { pDB1282 }\end{array}$ & $\begin{array}{c}\text { Co-expression of 6HMBPGggA-x4 } \\
\text { and GggB }\end{array}$ & This study \\
\hline $\begin{array}{c}\text { E. coli BL21(DE3) + } \\
\text { pRSFDuet-1_6HMBPgggA-R22_gggB + } \\
\text { pDB1282 }\end{array}$ & $\begin{array}{c}\text { Co-expression of 6HMBPGggA-R22 } \\
\text { and GggB }\end{array}$ & This study \\
\hline
\end{tabular}


Table S3. Primers used in this study. Restriction sites are underlined.

\begin{tabular}{|c|c|c|}
\hline Primer & Sequence $\left(5^{\prime} \rightarrow 3^{\prime}\right)$ & Purpose \\
\hline gggB_JIM8232_F (Ndel) & $\begin{array}{c}\text { CAAGCTCATATGATAAAGACAATA } \\
\text { GAAACAGATATAGGAAC }\end{array}$ & Cloning $g g g B$ into $\mathrm{pET}-28 \mathrm{~b}(+)$ \\
\hline gggB_JIM8232_R (BamHI) & $\begin{array}{c}\text { TCGATTGGATCCTTTTCGTTACAT } \\
\text { AACTCCTAAGCATAGC }\end{array}$ & Cloning $g g g B$ into $\mathrm{pET}-28 \mathrm{~b}(+)$ \\
\hline Duet_gggB_F (Ndel) & $\begin{array}{c}\text { ACGGTGCATATGATAAAGACCATC } \\
\text { GAGACTGACATCG }\end{array}$ & $\begin{array}{c}\text { Cloning } g g g B \text { into pRSFDuet-1 } \\
\text { at MCS2 }\end{array}$ \\
\hline Duet_gggB_R (Xhol) & $\begin{array}{c}\text { GGTACCCTCGAGCTAAGCATAAC } \\
\text { GGATAAAACCCCGAAAG }\end{array}$ & $\begin{array}{c}\text { Cloning } g g g B \text { into pRSFDuet-1 } \\
\text { at MCS2 }\end{array}$ \\
\hline Duet_gggA_F (BamHI) & $\begin{array}{c}\text { CAGCCAGGATCCATGGAGAAACT } \\
\text { TCAGGTCATTGATTTAGAGG }\end{array}$ & $\begin{array}{l}\text { Cloning } g g g A \text { into pRSFDuet-1 } \\
\text { at MCS1 in frame with 6HMBP }\end{array}$ \\
\hline Duet_gggA_R (Pstl) & $\begin{array}{c}\text { GAAGGGCTGCAGTTAGCGTCCTC } \\
\text { CTCCACAAGAGTG }\end{array}$ & $\begin{array}{l}\text { Cloning } g g g A \text { into pRSFDuet-1 } \\
\text { at MCS1 in frame with 6HMBP }\end{array}$ \\
\hline Duet_gggA_F & $\begin{array}{c}\text { GTTCTGTTTCAGGGTCCGGAATTC } \\
\text { GGATCCATGGAGAAACTTCAGGT } \\
\text { CATTGATTTAGAG }\end{array}$ & $\begin{array}{l}\text { Cloning } g g g A \text { into pRSFDuet-1 } \\
\text { at MCS } 1 \text { in frame with } 6 \mathrm{HMBP}\end{array}$ \\
\hline Duet_gggA-1x_R & $\begin{array}{c}\text { TGCGGCCGCAAGCTTGTCGACCT } \\
\text { TAGCGGCCGCCTCCACATGAAGC } \\
\text { GTTGATGACGTATC }\end{array}$ & $\begin{array}{l}\text { Cloning } g g g A-1 \mathrm{x} \text { into } \\
\text { pRSFDuet- } 1 \text { at MCS1 }\end{array}$ \\
\hline Duet_gggA-2x_R & $\begin{array}{c}\text { GGCCGCAAGCTTGTCGACCTTAG } \\
\text { CGACCACCGCCGCAGCTGCGGCC } \\
\text { GCCTCCACATGAAG }\end{array}$ & $\begin{array}{l}\text { Cloning } g g g A-2 x \text { into } \\
\text { pRSFDuet- } 1 \text { at MCS1 }\end{array}$ \\
\hline Duet_gggA-3x_R & $\begin{array}{c}\text { CGGCCGCAAGCTTGTCGACCTTA } \\
\text { GCGGCCACCACCGCAGCTGCGAC } \\
\text { CACCGCCGCAGCTG }\end{array}$ & $\begin{array}{l}\text { Cloning } g g g A-3 x \text { into } \\
\text { pRSFDuet- } 1 \text { at MCS1 }\end{array}$ \\
\hline Duet_gggA-3x,C31S_R & $\begin{array}{c}\text { CGGCCGCAAGCTTGTCGACCT } \\
\text { TAGCGGCCACCACCGCAGCTG } \\
\text { CGA CCACCGCCGGAGCTG }\end{array}$ & $\begin{array}{l}\text { Cloning } g g g A-3 x, C 31 S \text { into } \\
\text { pRSFDuet- } 1 \text { at MCS1 }\end{array}$ \\
\hline Duet_gggA-4x_F (Notl) & $\begin{array}{c}\text { TCAACGCTTCATGTGGAGGCGGC } \\
\text { CGCAGCTGCGGCGGTGGTCGCA } \\
\text { GCTGCGGTGGTGGCC }\end{array}$ & $\begin{array}{l}\text { Cloning } g g g A-4 x \text { into } \\
\text { pRSFDuet- } 1 \text { at MCS1 }\end{array}$ \\
\hline Duet_gggA-4x_R & $\begin{array}{l}\text { GACTTAAGCATTATGCGGCCTTAG } \\
\text { CGGCCGCCGCCGCAGCTGCGGC } \\
\text { CACCACCGCAGCTG }\end{array}$ & $\begin{array}{l}\text { Cloning } g g g A-4 x \text { into } \\
\text { pRSFDuet- } 1 \text { at MCS1 }\end{array}$ \\
\hline Duet_gggA-R22_F & $\begin{array}{c}\text { GTTCTGTTTCAGGGTCCGGAATTC } \\
\text { GGATCCATGGAGAAACTTCAGGT } \\
\text { CATTGATTTAGAGGAATTGCTTGA } \\
\text { GTTTGACCAAGGATACGTCATC }\end{array}$ & $\begin{array}{l}\text { Cloning } g g g A-R 22 \text { into } \\
\text { pRSFDuet- } 1 \text { at MCS1 }\end{array}$ \\
\hline Duet_gggA-R22_R & $\begin{array}{c}\text { GGCCGCAAGCTTGTCGACCTTAG } \\
\text { CGTCCTCCTCCACAAGAGTGCGA } \\
\text { CGGTCCACATGAAGCGTTCCTGAT } \\
\text { GACGTATCCTTGGTCAAACTC }\end{array}$ & $\begin{array}{l}\text { Cloning } g g g A-R 22 \text { into } \\
\text { pRSFDuet-1 at MCS1 }\end{array}$ \\
\hline
\end{tabular}


Table S4. HR-MS data for GggA peptides in enzymatic assays.

\begin{tabular}{|c|c|c|c|c|c|c|c|}
\hline & & \multicolumn{3}{|c|}{ Substrate } & \multicolumn{3}{|c|}{ Product } \\
\hline & Ion & Calc & Obs & $\Delta \mathrm{ppm}$ & Calc & Obs & $\Delta \mathrm{ppm}$ \\
\hline \multirow{3}{*}{ wild-type } & {$[\mathrm{M}+2 \mathrm{H}]^{2+}$} & 1897.89477 & 1897.89487 & 0.1 & 1895.87912 & 1895.88351 & 2.3 \\
\hline & {$[\mathrm{M}+3 \mathrm{H}]^{3+}$} & 1265.59894 & 1265.60102 & 1.6 & 1264.25517 & 1264.26001 & 3.8 \\
\hline & {$[\mathrm{M}+4 \mathrm{H}]^{4+}$} & 949.45102 & 949.45376 & 2.9 & 948.44320 & 948.44813 & 5.2 \\
\hline \multirow{2}{*}{ S28A } & {$[\mathrm{M}+3 \mathrm{H}]^{3+}$} & 1260.26730 & 1260.27092 & 2.9 & 1258.92353 & 1258.92909 & 4.4 \\
\hline & {$[\mathrm{M}+4 \mathrm{H}]^{4+}$} & 945.45229 & 945.45629 & 4.2 & 944.44447 & 944.44993 & 5.8 \\
\hline \multirow{2}{*}{${ }^{13} \mathrm{C}_{2},{ }^{15} \mathrm{~N}-\mathrm{G} 34$} & {$[\mathrm{M}+3 \mathrm{H}]^{3+}$} & 1266.60018 & 1266.60122 & 0.8 & 1265.25642 & 1265.26221 & 4.6 \\
\hline & {$[\mathrm{M}+4 \mathrm{H}]^{4+}$} & 950.20196 & 950.20392 & 2.1 & 949.19413 & 949.20000 & 6.2 \\
\hline \multirow{2}{*}{ C25S } & {$[\mathrm{M}+3 \mathrm{H}]^{3+}$} & 1260.27322 & 1260.26927 & 3.1 & 1259.60133 & 1259.59689 & 3.5 \\
\hline & {$[\mathrm{M}+4 \mathrm{H}]^{4+}$} & 945.45673 & 945.45426 & 2.6 & 944.95282 & 944.94976 & 3.2 \\
\hline \multirow{3}{*}{ C31S } & {$[\mathrm{M}+2 \mathrm{H}]^{2+}$} & 1889.90619 & 1889.90770 & 0.8 & \multirow{3}{*}{\multicolumn{3}{|c|}{ No Reaction }} \\
\hline & {$[\mathrm{M}+3 \mathrm{H}]^{3+}$} & 1260.27322 & 1260.27587 & 2.1 & & & \\
\hline & {$[\mathrm{M}+4 \mathrm{H}]^{4+}$} & 945.45673 & 945.46014 & 3.6 & & & \\
\hline \multirow{3}{*}{$\alpha-{ }^{2} \mathrm{H}_{2}-\mathrm{G} 34$} & $\mathrm{M}+2 \mathrm{H}]^{2+}$ & 1898.90104 & 1898.90403 & 1.6 & 1896.38226 & 1896.38054 & 0.9 \\
\hline & {$[\mathrm{M}+3 \mathrm{H}]^{3+}$} & 1266.26979 & 1266.27236 & 2.0 & 1264.59060 & 1264.59101 & 0.3 \\
\hline & {$[\mathrm{M}+4 \mathrm{H}]^{4+}$} & 949.95416 & 949.95724 & 3.2 & 948.69477 & 948.69573 & 1.0 \\
\hline \multirow{3}{*}{$\alpha-{ }^{2} \mathrm{H}_{1}-\mathrm{A} 28$} & $\mathrm{M}+2 \mathrm{H}]^{2+}$ & 1890.40045 & 1890.40338 & 1.5 & 1887.88166 & 1887.88944 & 4.1 \\
\hline & {$[\mathrm{M}+3 \mathrm{H}]^{3+}$} & 1260.60272 & 1260.60633 & 2.9 & 1258.92353 & 1258.92904 & 4.4 \\
\hline & {$[\mathrm{M}+4 \mathrm{H}]^{4+}$} & 945.70386 & 945.70744 & 3.8 & 944.44447 & 944.44960 & 5.4 \\
\hline \multirow{2}{*}{$\beta-{ }^{2} \mathrm{H}_{3}-\mathrm{A} 28$} & {$[\mathrm{M}+3 \mathrm{H}]^{3+}$} & 1261.27358 & 1261.27545 & 1.5 & 1259.92981 & 1259.93296 & 2.5 \\
\hline & {$[\mathrm{M}+4 \mathrm{H}]^{4+}$} & 946.20700 & 946.20915 & 2.3 & 945.19918 & 945.20233 & 3.3 \\
\hline \multirow{2}{*}{ N-Me-A28 } & {$[\mathrm{M}+3 \mathrm{H}]^{3+}$} & 1264.93918 & 1264.93753 & 1.3 & 1264.26730 & 1264.26598 & 1.0 \\
\hline & {$[\mathrm{M}+4 \mathrm{H}]^{4+}$} & 948.95621 & 948.95560 & 0.6 & 948.45229 & 948.45202 & 0.3 \\
\hline \multirow{2}{*}{ N-Me-S28 } & {$[\mathrm{M}+3 \mathrm{H}]^{3+}$} & 1270.27082 & 1270.27108 & 0.2 & 1269.59894 & 1269.59831 & 0.5 \\
\hline & {$[\mathrm{M}+4 \mathrm{H}]^{4+}$} & 952.95493 & 952.95666 & 1.8 & 952.45102 & 952.45210 & 1.1 \\
\hline \multirow{3}{*}{ N-Me-G34 } & $\mathrm{M}+2 \mathrm{H}]^{2+}$ & 1904.90259 & 1904.90087 & 0.9 & \multirow{3}{*}{\multicolumn{3}{|c|}{ No Reaction }} \\
\hline & {$[\mathrm{M}+3 \mathrm{H}]^{3+}$} & 1270.27082 & 1270.27123 & 0.3 & & & \\
\hline & {$[\mathrm{M}+4 \mathrm{H}]^{4+}$} & 952.95493 & 952.95623 & 1.4 & & & \\
\hline
\end{tabular}


Table S5. HR-MS/MS data for the product of the GggB reaction with wt GggA substrate.

\begin{tabular}{|c|c|c|c|}
\hline Ion & Calc $\mathrm{m} / \mathrm{z}$ & Obs $\mathrm{m} / \mathrm{z}$ & $\Delta \mathrm{ppm}$ \\
\hline $\mathrm{b}_{2}{ }^{+1}$ & 261.0904 & 261.0898 & 2.3 \\
\hline$b_{3}^{+1}$ & 389.1853 & 389.1840 & 3.3 \\
\hline $\mathrm{b}_{4}^{+1}$ & 502.2694 & 502.2682 & 2.4 \\
\hline$b_{5}^{+1}$ & 630.3280 & 630.3262 & 2.9 \\
\hline$b_{6}^{+1}$ & 729.3964 & 729.3942 & 3.0 \\
\hline $\mathrm{b}_{7}^{+1}$ & 842.4804 & 842.4787 & 2.0 \\
\hline $\mathrm{b}_{8}^{+1}$ & 957.5074 & 957.5045 & 3.0 \\
\hline$b_{9}^{+1}$ & 1070.5914 & 1070.5862 & 4.9 \\
\hline$b_{10}+1$ & 1199.6340 & 1199.6272 & 5.7 \\
\hline$b_{11}^{+1}$ & 1328.6766 & 1328.6663 & 7.8 \\
\hline$b_{12}^{+1}$ & 1441.7607 & 1441.7607 & 0.0 \\
\hline$b_{11}+2$ & 664.8420 & 664.8421 & 0.2 \\
\hline $\mathrm{y}_{1}^{+1}$ & 175.1190 & 175.1178 & 6.9 \\
\hline$y_{2}+1$ & 230.1248 & 230.1240 & 3.5 \\
\hline $\mathrm{y}_{5}^{+1}$ & 447.1769 & 447.1743 & 5.8 \\
\hline $\mathrm{y}_{6}^{+1}$ & 534.2089 & 534.2069 & 3.7 \\
\hline$y_{7}^{+1}$ & 671.2678 & 671.2666 & 1.8 \\
\hline $\mathrm{y}_{8}^{+1}$ & 756.2842 & 756.2817 & 3.3 \\
\hline $\mathrm{y}_{9}^{+1}$ & 853.3370 & 853.3353 & 2.0 \\
\hline $\mathrm{y}_{10}+1$ & 910.3584 & 910.3541 & 4.7 \\
\hline $\mathrm{y}_{11}^{+1}$ & 1013.3676 & 1013.3638 & 3.7 \\
\hline $\mathrm{y}_{12}+1$ & 1100.3996 & 1100.3957 & 3.5 \\
\hline $\mathrm{y}_{13}+1$ & 1171.4368 & 1171.4342 & 2.2 \\
\hline $\mathrm{y}_{14}^{+1}$ & 1285.4797 & 1285.4769 & 2.2 \\
\hline $\mathrm{y}_{15}{ }^{+1}$ & 1398.5637 & 1398.5596 & 2.9 \\
\hline$y_{16}{ }^{+1}$ & 1497.6322 & 1497.6257 & 4.3 \\
\hline $\mathrm{y}_{14}{ }^{+2}$ & 643.2435 & 643.2420 & 2.3 \\
\hline $\mathrm{y}_{15}^{+2}$ & 699.7855 & 699.7832 & 3.3 \\
\hline$y_{16}^{+2}$ & 749.3197 & 749.3190 & 0.9 \\
\hline $\mathrm{y}_{17}^{+2}$ & 830.8514 & 830.8523 & 1.1 \\
\hline $\mathrm{y}_{18}^{+2}$ & 859.3621 & 859.3569 & 6.1 \\
\hline $\mathrm{y}_{19}{ }^{+2}$ & 923.3914 & 923.3893 & 2.3 \\
\hline $\mathrm{y}_{20}{ }^{+2}$ & 980.9049 & 980.8990 & 6.0 \\
\hline$y_{21}{ }^{+2}$ & 1054.4391 & 1054.4364 & 2.6 \\
\hline$y_{22}+2$ & 1118.9604 & 1118.9582 & 2.0 \\
\hline $\mathrm{y}_{23}{ }^{+2}$ & 1175.5024 & 1175.4997 & 2.3 \\
\hline$y_{26}^{+2}$ & 1361.0870 & 1361.0828 & 3.1 \\
\hline $\mathrm{y}_{27}{ }^{+2}$ & 1417.6291 & 1417.6251 & 2.8 \\
\hline $\mathrm{y}_{28}^{+2}$ & 1475.1425 & 1475.1402 & 1.6 \\
\hline$y_{33}^{+3}$ & 1177.5608 & 1177.5583 & 2.1 \\
\hline $\mathrm{MH}-\mathrm{H}_{2} \mathrm{O}^{+3}$ & 1258.2516 & 1258.2494 & 1.7 \\
\hline $\mathrm{MH}-\mathrm{NH}_{3}{ }^{+3}$ & 1258.5797 & 1258.5825 & 2.2 \\
\hline $\mathrm{MH}^{+3}$ & 1264.2552 & 1264.2555 & 0.2 \\
\hline
\end{tabular}


Table S6. HR-MS/MS data for the product of th GggB reaction with ${ }^{13} \mathrm{C}_{2},{ }^{15} \mathrm{~N}-\mathrm{G} 34-\mathrm{GggA}$ substrate. Observed fragments are also indicated in the illustration below the table.

\begin{tabular}{cccc}
\hline Ion & Calc $\mathrm{m} / \mathrm{z}$ & Obs m/z & $\Delta$ ppm \\
\hline $\mathrm{b}_{2}{ }^{+1}$ & 261.0904 & 261.0895 & 3.4 \\
$\mathrm{~b}_{3}{ }^{+1}$ & 389.1853 & 389.1824 & 7.5 \\
$\mathrm{~b}_{4}{ }^{+1}$ & 502.2694 & 502.2699 & 1.0 \\
$\mathrm{~b}_{5}{ }^{+1}$ & 630.3280 & 630.3255 & 4.0 \\
$\mathrm{~b}_{6}{ }^{+1}$ & 729.3964 & 729.3930 & 4.7 \\
$\mathrm{~b}_{7}{ }^{+1}$ & 842.4804 & 842.4748 & 6.6 \\
\hline $\mathrm{y}_{1}{ }^{+1}$ & 175.1190 & 175.1180 & 5.7 \\
$\mathrm{y}_{2}{ }^{+1}$ & 233.1285 & 233.1273 & 5.1 \\
$\mathrm{y}_{5}{ }^{+1}$ & 450.1806 & 450.1820 & 3.1 \\
$\mathrm{y}_{6}{ }^{+1}$ & 537.2127 & 537.2137 & 1.9 \\
$\mathrm{y}_{7}{ }^{+1}$ & 674.2716 & 674.2702 & 2.1 \\
$\mathrm{y}_{8}{ }^{+1}$ & 759.2879 & 759.2839 & 5.3 \\
$\mathrm{y}_{10}{ }^{+1}$ & 913.3622 & 913.3566 & 6.1 \\
$\mathrm{y}_{14}{ }^{+1}$ & 1288.4834 & 1288.4840 & 0.5 \\
$\mathrm{y}_{15}{ }^{+1}$ & 1401.5675 & 1401.5776 & 7.2 \\
$\mathrm{y}_{28}{ }^{+2}$ & 1476.6444 & 1476.6537 & 6.3 \\
$\mathrm{y}_{29}{ }^{+2}$ & 1533.1864 & 1533.1893 & 1.9 \\
$\mathrm{y}_{31}{ }^{+2}$ & 1646.7499 & 1646.7581 & 5.0 \\
$\mathrm{y}_{32}{ }^{2}$ & 1703.2920 & 1703.3033 & 6.6 \\
\hline $\mathrm{MH} \mathrm{H}_{2} \mathrm{O}^{+3}$ & 1259.2529 & 1259.2541 & 1.0 \\
$\mathrm{MH} \mathrm{NH}_{3}{ }^{+3}$ & 1259.5809 & 1259.5785 & 1.9 \\
$\mathrm{MH}^{+3}$ & 1265.2564 & 1265.2574 & 0.8 \\
\hline
\end{tabular}

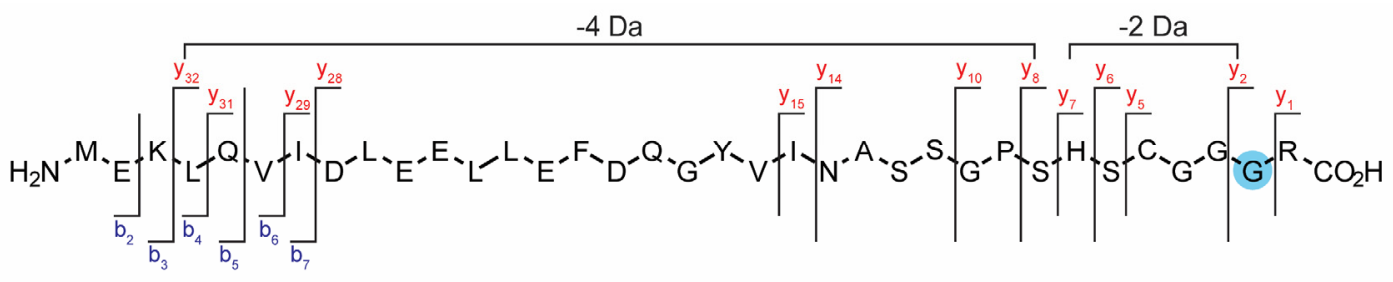

Table S7. NMR assignments for residue $\mathrm{G} 34$ in ${ }^{13} \mathrm{C}_{2},{ }^{15} \mathrm{~N}_{1}-\mathrm{G} 34-\mathrm{GggA}$ substate and product.

\begin{tabular}{ccccc}
\hline & \multicolumn{2}{c}{ Substrate } & \multicolumn{2}{c}{ Product } \\
\hline & $\delta \mathrm{H}$ & $\delta \mathrm{C}$ & $\delta \mathrm{H}$ & $\delta \mathrm{C}$ \\
\hline 1 & - & 170.5 & - & 167.8 \\
2 & 3.91 & 42.5 & 5.48 & 54.0 \\
\hline
\end{tabular}


Table S8. HR-MS/MS data for the product of the GggB reaction with S28A-GggA substrate. Observed fragments are also indicated in the illustration below the table.

\begin{tabular}{cccc}
\hline lon & Calc $\mathrm{m} / \mathrm{z}$ & Obs $\mathrm{m} / \mathrm{z}$ & $\Delta \mathrm{ppm}$ \\
\hline $\mathrm{b}_{2}{ }^{+1}$ & 261.0904 & 261.0901 & 1.1 \\
$\mathrm{~b}_{3}{ }^{+1}$ & 389.1853 & 389.1852 & 0.3 \\
$\mathrm{~b}_{4}{ }^{+1}$ & 502.2694 & 502.2716 & 4.4 \\
$\mathrm{~b}_{5}{ }^{+1}$ & 630.3280 & 630.3293 & 2.1 \\
$\mathrm{~b}_{6}{ }^{+1}$ & 729.3964 & 729.3974 & 1.4 \\
$\mathrm{~b}_{7}{ }^{+1}$ & 842.4804 & 842.4814 & 1.2 \\
$\mathrm{~b}_{8}{ }^{+1}$ & 957.5074 & 957.5145 & 7.4 \\
$\mathrm{~b}_{9}{ }^{+1}$ & 1070.5914 & 1070.5915 & 0.1 \\
$\mathrm{~b}_{12}{ }^{+1}$ & 1441.7607 & 1441.7728 & 8.4 \\
\hline $\mathrm{y}_{1}{ }^{+1}$ & 175.1190 & 175.1189 & 0.6 \\
$\mathrm{y}_{2}{ }^{+1}$ & 230.1248 & 230.1238 & 4.3 \\
$\mathrm{y}_{5}{ }^{+1}$ & 447.1769 & 447.1772 & 0.7 \\
$\mathrm{y}_{6}{ }^{+1}$ & 534.2089 & 534.2087 & 0.4 \\
$\mathrm{y}_{7}{ }^{+1}$ & 671.2678 & 671.2710 & 4.8 \\
$\mathrm{y}_{8}{ }^{+1}$ & 740.2893 & 740.2897 & 0.5 \\
$\mathrm{y}_{10}{ }^{+1}$ & 894.3635 & 894.3664 & 3.2 \\
$\mathrm{y}_{11}{ }^{+1}$ & 997.3727 & 997.3725 & 0.2 \\
$\mathrm{y}_{12}{ }^{+1}$ & 1084.4047 & 1084.4043 & 0.4 \\
$\mathrm{y}_{13}{ }^{+1}$ & 1155.4418 & 1155.4466 & 4.2 \\
$\mathrm{y}_{14}{ }^{+1}$ & 1269.4848 & 1269.4909 & 4.8 \\
$\mathrm{y}_{15}{ }^{+1}$ & 1382.5688 & 1382.5621 & 4.8 \\
$\mathrm{y}_{15}{ }^{+2}$ & 691.7881 & 691.7888 & 1.0 \\
$\mathrm{y}_{18}{ }^{+2}$ & 851.3647 & 851.3618 & 3.4 \\
$\mathrm{y}_{20}{ }^{+2}$ & 972.9074 & 972.9057 & 1.7 \\
$\mathrm{y}_{23}{ }^{+2}$ & 1167.5050 & 1167.4972 & 6.7 \\
$\mathrm{y}_{29}{ }^{+2}$ & 1523.6871 & 1523.6817 & 3.5 \\
$\mathrm{y}_{32}{ }^{+2}$ & 1693.7926 & 1693.7753 & 10.2 \\
\hline $\mathrm{MH}^{+4}$ & 944.4445 & 944.4422 & 2.4 \\
\hline & & &
\end{tabular}

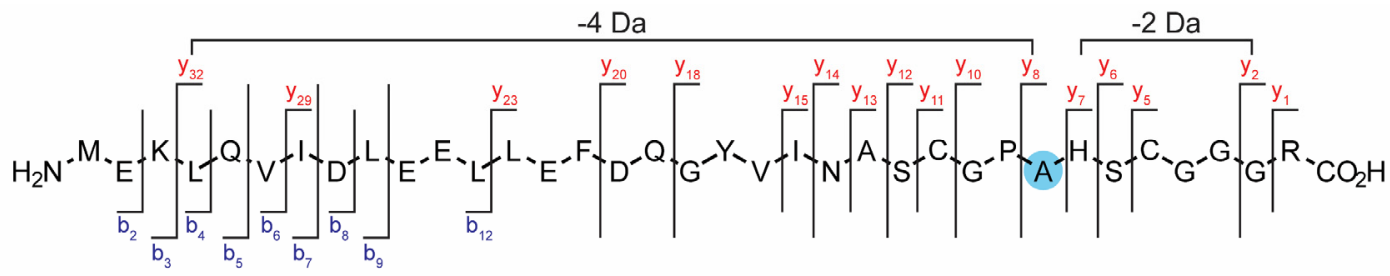

Table S9. NMR assignments for residue A28 in ${ }^{13} \mathrm{C}_{3}-\mathrm{A} 28-\mathrm{GggA}$ substrate and product.

\begin{tabular}{ccccc}
\hline & \multicolumn{2}{c}{ Substrate } & \multicolumn{2}{c}{ Product } \\
\hline & $\delta \mathrm{H}$ & $\delta \mathrm{C}$ & $\delta \mathrm{H}$ & $\delta \mathrm{C}$ \\
\hline 1 & - & 174.7 & - & 172.0 \\
2 & 4.22 & 49.7 & - & 65.7 \\
3 & 1.32 & 15.8 & 1.67 & 25.0 \\
\hline
\end{tabular}


Table S10. HR-MS/MS data for the product of the GggB reaction with C25S-GggA substrate. Observed fragments are also indicated in the illustration below the table (page S20).

\begin{tabular}{|c|c|c|c|}
\hline Ion & Calc $\mathrm{m} / \mathrm{z}$ & Obs $\mathrm{m} / \mathrm{z}$ & $\Delta p p m$ \\
\hline $\mathrm{b}_{2}{ }^{+1}$ & 261.0904 & 261.08774 & 10.2 \\
\hline $\mathrm{b}_{3}+1$ & 389.1853 & 389.18263 & 6.9 \\
\hline $\mathrm{b}_{4}^{+1}$ & 502.2694 & 502.26695 & 4.9 \\
\hline$b_{5}^{+1}$ & 630.3280 & 630.32410 & 6.2 \\
\hline$b_{6}^{+1}$ & 729.3964 & 729.39128 & 7.0 \\
\hline $\mathrm{b}_{7}^{+1}$ & 842.4804 & 842.47333 & 8.4 \\
\hline $\mathrm{b}_{8}^{+1}$ & 957.5074 & 957.49851 & 9.3 \\
\hline$b_{9}^{+1}$ & 1070.5914 & 1070.58769 & 3.5 \\
\hline $\mathrm{b}_{11}{ }^{+2}$ & 664.8420 & 664.83731 & 7.1 \\
\hline $\mathrm{y}_{1}^{+1}$ & 175.1190 & 175.11644 & 14.6 \\
\hline $\mathrm{y}_{2}^{+1}$ & 230.1248 & 230.12192 & 12.5 \\
\hline $\mathrm{y}_{3}^{+1}$ & 344.1677 & 344.17193 & 12.3 \\
\hline $\mathrm{y}_{5}^{+1}$ & 447.1769 & 447.17491 & 4.5 \\
\hline$y_{6}^{+1}$ & 534.2089 & 534.20404 & 9.1 \\
\hline$y_{7}^{+1}$ & 671.2678 & 671.26290 & 7.3 \\
\hline $\mathrm{y}_{8}^{+1}$ & 758.2998 & 758.28967 & 13.4 \\
\hline $\mathrm{y}_{9}^{+1}$ & 855.3526 & 855.34778 & 5.6 \\
\hline$y_{10}^{+1}$ & 912.3741 & 912.36611 & 8.8 \\
\hline $\mathrm{y}_{11}{ }^{+1}$ & 999.4061 & 999.39630 & 9.8 \\
\hline $\mathrm{y}_{12}^{+1}$ & 1086.4381 & 1086.43215 & 5.5 \\
\hline $\mathrm{y}_{13}+1$ & 1157.4752 & 1157.46456 & 9.2 \\
\hline $\mathrm{y}_{14}^{+1}$ & 1271.5182 & 1271.51101 & 5.7 \\
\hline $\mathrm{y}_{15}+1$ & 1384.6022 & 1384.58614 & 11.6 \\
\hline $\mathrm{y}_{116}^{+1}$ & 1483.6706 & 1483.65588 & 9.9 \\
\hline $\mathrm{y}_{18}^{+1}$ & 1703.7554 & 1703.74571 & 5.7 \\
\hline $\mathrm{y}_{19}{ }^{+1}$ & 1831.8140 & 1831.80136 & 6.9 \\
\hline $\mathrm{y}_{9}^{+2}$ & 428.1799 & 428.17491 & 11.7 \\
\hline$y_{10}+2$ & 456.6907 & 456.68696 & 8.2 \\
\hline$y_{11}+2$ & 500.2067 & 500.20910 & 4.8 \\
\hline $\mathrm{y}_{12}+2$ & 543.7227 & 543.71807 & 8.5 \\
\hline $\mathrm{y}_{13}+2$ & 579.2413 & 579.23591 & 9.3 \\
\hline$y_{14}+2$ & 636.2627 & 636.26277 & 0.1 \\
\hline$y_{15}^{+2}$ & 692.8048 & 692.80043 & 6.3 \\
\hline$y_{16}{ }^{+2}$ & 742.3390 & 742.32883 & 13.7 \\
\hline $\mathrm{y}_{18}^{+2}$ & 852.3814 & 852.36892 & 14.6 \\
\hline $\mathrm{y}_{19}^{+2}$ & 916.4106 & 916.40406 & 7.1 \\
\hline $\mathrm{y}_{21}+2$ & 1047.4583 & 1047.44885 & 9.0 \\
\hline$y_{22}+2$ & 1111.9796 & 1111.97151 & 7.3 \\
\hline$y_{24}+2$ & 1225.0637 & 1225.05693 & 5.5 \\
\hline$y_{25}^{+2}$ & 1289.5850 & 1289.58755 & 2.0 \\
\hline $\mathrm{y}_{27}^{+2}$ & 1410.6483 & 1410.63438 & 9.9 \\
\hline$y_{28}^{+2}$ & 1468.1618 & 1468.15224 & 6.5 \\
\hline $\mathrm{y}_{29}+2$ & 1524.7038 & 1524.69146 & 8.1 \\
\hline $\mathrm{y}_{30}+2$ & 1574.2380 & 1574.22621 & 7.5 \\
\hline $\mathrm{y}_{31}+2$ & 1638.2673 & 1638.25891 & 5.1 \\
\hline$y_{32}+2$ & 1694.8093 & 1694.80812 & 0.7 \\
\hline $\mathrm{y}_{33}{ }^{+3}$ & 1172.9070 & 1172.89968 & 6.2 \\
\hline $\mathrm{MH}-\mathrm{H}_{2} \mathrm{O}^{+3}$ & 1253.5978 & 1253.61085 & 10.4 \\
\hline $\mathrm{MH}-\mathrm{NH}_{3}{ }^{+3}$ & 1253.9258 & 1253.92272 & 2.5 \\
\hline $\mathrm{MH}^{+3}$ & 1259.6013 & 1259.59633 & 3.9 \\
\hline
\end{tabular}




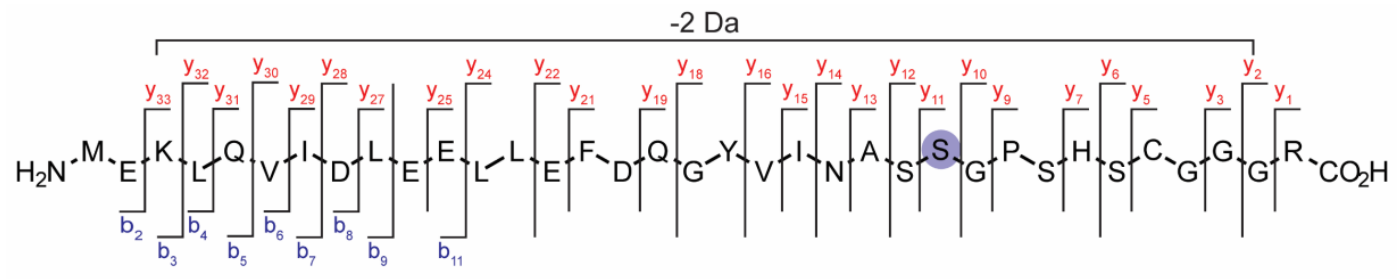

Table S11. HR-MS/MS data for product of GggB reaction with $\alpha-{ }^{2} \mathrm{H}_{2}-\mathrm{G} 34-\mathrm{GggA}$. Observed fragments are also indicated in the illustration below the table (page S21).

\begin{tabular}{|c|c|c|c|}
\hline Ion & Calc $\mathrm{m} / \mathrm{z}$ & Obs $\mathrm{m} / \mathrm{z}$ & $\Delta \mathrm{ppm}$ \\
\hline $\mathrm{b}_{2}^{+1}$ & 261.0904 & 261.0879 & 9.6 \\
\hline$b_{3}^{+1}$ & 389.1853 & 389.1835 & 4.6 \\
\hline $\mathrm{b}_{4}^{+1}$ & 502.2694 & 502.2650 & 8.8 \\
\hline$b_{5}^{+1}$ & 630.3280 & 630.3250 & 4.8 \\
\hline$b_{6}^{+1}$ & 729.3964 & 729.3929 & 4.8 \\
\hline $\mathrm{b}_{7}^{+1}$ & 842.4804 & 842.4709 & 11.3 \\
\hline $\mathrm{b}_{8}^{+1}$ & 957.5074 & 957.4996 & 8.1 \\
\hline$b_{9}^{+1}$ & 1070.5914 & 1070.5806 & 10.1 \\
\hline$b_{10}{ }^{+1}$ & 1199.6340 & 1199.6328 & 1.0 \\
\hline$b_{11}{ }^{+1}$ & 1328.6766 & 1328.6704 & 4.7 \\
\hline$b_{12}^{+1}$ & 1441.7607 & 1441.7504 & 7.1 \\
\hline$b_{13}+1$ & 1554.8448 & 1554.8506 & 3.7 \\
\hline $\mathrm{b}_{8}^{+2}$ & 479.2573 & 479.2534 & 8.1 \\
\hline$b_{9}^{+2}$ & 535.7994 & 535.7958 & 6.7 \\
\hline$b_{11}{ }^{+2}$ & 664.8420 & 664.8379 & 6.2 \\
\hline$b_{12}{ }^{+2}$ & 721.3840 & 721.3806 & 4.7 \\
\hline$y_{1}^{+1}$ & 175.1190 & 175.1165 & 14.3 \\
\hline$y_{2}+1$ & 231.1310 & 231.1290 & 8.7 \\
\hline$y_{4}^{+1}$ & 345.1740 & 345.1701 & 11.3 \\
\hline$y_{5}^{+1}$ & 448.1832 & 448.1812 & 4.5 \\
\hline $\mathrm{y}_{6}^{+1}$ & 535.2152 & 535.2097 & 10.3 \\
\hline$y_{7}^{+1}$ & 672.2741 & 672.2709 & 4.8 \\
\hline $\mathrm{y}_{8}^{+1}$ & 757.2905 & 757.2856 & 6.5 \\
\hline $\mathrm{y}_{10}+1$ & 911.3647 & 911.3570 & 8.4 \\
\hline$y_{11}+1$ & 1014.3739 & 1014.3649 & 8.9 \\
\hline$y_{12}{ }^{+1}$ & 1101.4059 & 1101.4028 & 2.8 \\
\hline$y_{13}+1$ & 1172.4430 & 1172.4461 & 2.6 \\
\hline $\mathrm{y}_{14}+1$ & 1286.4860 & 1286.4814 & 3.6 \\
\hline$y_{15}+1$ & 1399.5700 & 1399.5621 & 5.6 \\
\hline$y_{7}^{++2}$ & 336.6407 & 336.6393 & 4.2 \\
\hline$y_{11}+2$ & 507.6906 & 507.6939 & 6.5 \\
\hline$y_{12}+2$ & 551.2066 & 551.2010 & 10.2 \\
\hline$y_{13}+2$ & 586.7252 & 586.7290 & 6.5 \\
\hline $\mathrm{y}_{14}+2$ & 643.7466 & 643.7432 & 5.3 \\
\hline$y_{15}+2$ & 700.2886 & 700.2848 & 5.4 \\
\hline$y_{16}+2$ & 749.8229 & 749.8198 & 4.1 \\
\hline$y_{17}+2$ & 831.3545 & 831.3498 & 5.7 \\
\hline $\mathrm{y}_{18}+2$ & 859.8653 & 859.8649 & 0.5 \\
\hline $\mathrm{y}_{19}{ }^{+2}$ & 923.8945 & 923.8873 & 7.8 \\
\hline
\end{tabular}




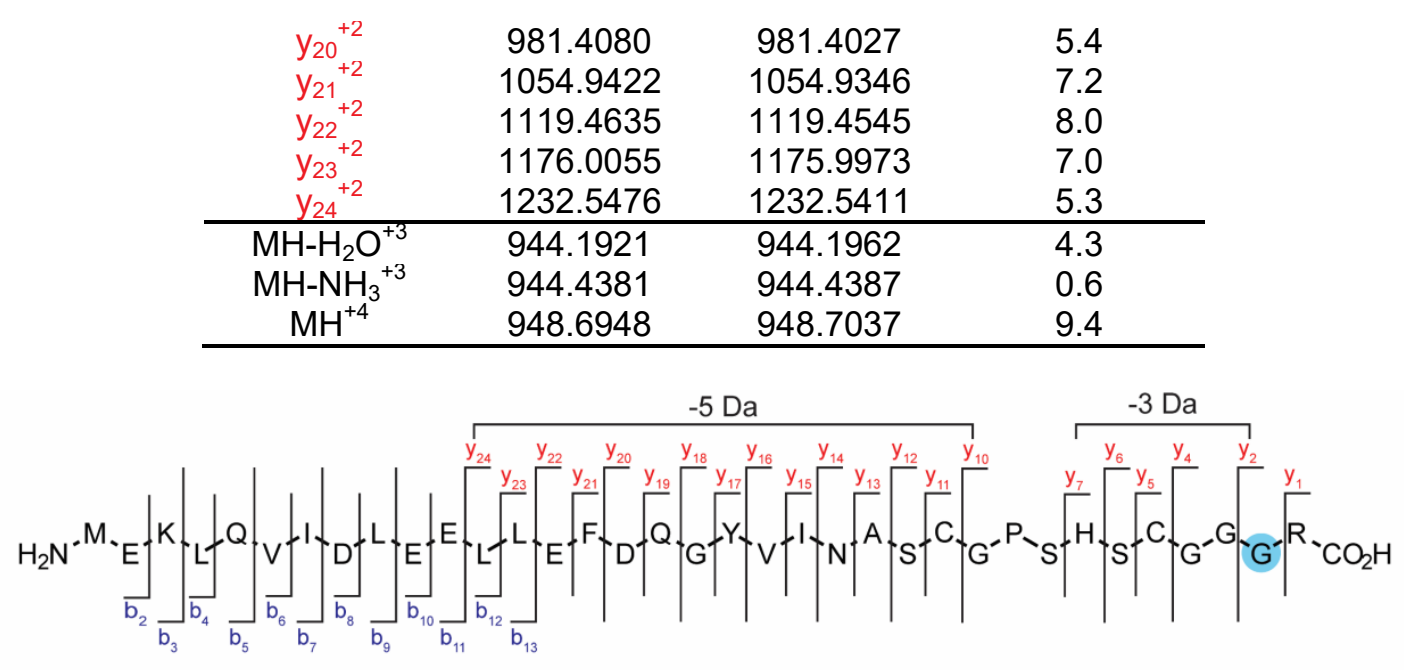

Table S12. HR-MS/MS data for product of GggB reaction with $\alpha-{ }^{2} \mathrm{H}_{1}-\mathrm{A} 28-\mathrm{GggA}$ substrate. Observed fragments are also indicated in the illustration below the table.

\begin{tabular}{cccc}
\hline Ion & Calc m/z & Obs m/z & $\Delta$ ppm \\
\hline $\mathrm{b}_{2}{ }^{+1}$ & 261.0904 & 261.0873 & 11.9 \\
$\mathrm{~b}_{3}{ }^{+1}$ & 389.1853 & 389.1832 & 5.4 \\
$\mathrm{~b}_{4}{ }^{+1}$ & 502.2694 & 502.2669 & 5.0 \\
$\mathrm{~b}_{5}{ }^{+1}$ & 630.3280 & 630.3238 & 6.7 \\
$\mathrm{~b}_{6}{ }^{+1}$ & 729.3964 & 729.3937 & 3.7 \\
$\mathrm{~b}_{7}{ }^{+1}$ & 842.4804 & 842.4726 & 9.3 \\
\hline $\mathrm{y}_{1}{ }^{+1}$ & 175.1190 & 175.1170 & 11.4 \\
$\mathrm{y}_{2}{ }^{+1}$ & 230.1248 & 230.1219 & 12.6 \\
$\mathrm{y}_{5}{ }^{+1}$ & 447.1769 & 447.1711 & 13.0 \\
$\mathrm{y}_{6}{ }^{+1}$ & 534.2089 & 534.2038 & 9.5 \\
$\mathrm{y}_{8}{ }^{+1}$ & 740.2893 & 740.2855 & 5.1 \\
$\mathrm{y}_{10}{ }^{+1}$ & 894.3635 & 894.3704 & 7.7 \\
$\mathrm{y}_{12}{ }^{+1}$ & 1084.4047 & 1084.3963 & 7.7 \\
$\mathrm{y}_{13}{ }^{+1}$ & 1155.4418 & 1155.4391 & 2.3 \\
$\mathrm{y}_{14}{ }^{+1}$ & 1269.4848 & 1269.4830 & 1.4 \\
$\mathrm{y}_{15}{ }^{+1}$ & 1382.5688 & 1382.5628 & 4.3 \\
$\mathrm{y}_{16}{ }^{+1}$ & 1481.6372 & 1481.6287 & 5.7 \\
$\mathrm{y}_{29}{ }^{+2}$ & 1523.6871 & 1523.6834 & 2.4 \\
$\mathrm{y}_{30}{ }^{+2}$ & 1573.2213 & 1573.2202 & 0.7 \\
\hline${\mathrm{MH}-\mathrm{H}_{2} \mathrm{O}^{+3}}_{\mathrm{MH} \mathrm{NH}_{3}{ }^{+3}}^{1252.9200}$ & 1252.9201 & 0.1 \\
$\mathrm{MH}^{+3}$ & 1253.2480 & 1253.2460 & 1.6 \\
\hline
\end{tabular}

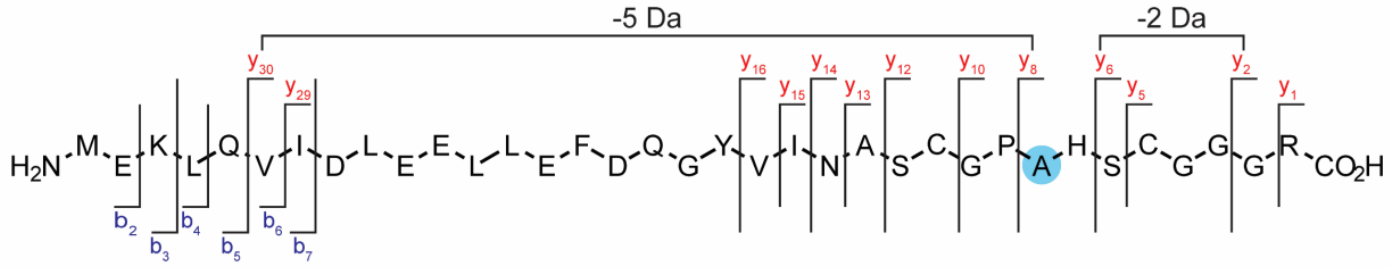


Table S13. HR-MS/MS data for product of $\mathrm{GggB}$ reaction with $\beta-{ }^{2} \mathrm{H}_{3}-\mathrm{A} 28-\mathrm{GggA}$ substrate. Observed fragments are also indicated in the illustration below the table.

\begin{tabular}{|c|c|c|c|}
\hline Ion & Calc $\mathrm{m} / \mathrm{z}$ & Obs $\mathrm{m} / \mathrm{z}$ & $\Delta \mathrm{ppm}$ \\
\hline $\mathrm{b}_{2}^{+1}$ & 261.0904 & 261.0892 & 4.6 \\
\hline $\mathrm{b}_{3}+1$ & 389.1853 & 389.1847 & 1.5 \\
\hline $\mathrm{b}_{4}^{+1}$ & 502.2694 & 502.2681 & 2.6 \\
\hline $\mathrm{b}_{5}^{+1}$ & 630.3280 & 630.3252 & 4.4 \\
\hline $\mathrm{b}_{6}^{+1}$ & 729.3964 & 729.3946 & 2.5 \\
\hline $\mathrm{b}_{7}^{+1}$ & 842.4804 & 842.4764 & 4.7 \\
\hline$b_{8}^{+1}$ & 957.5074 & 957.5046 & 2.9 \\
\hline $\mathrm{b}_{10}^{+1}$ & 1199.6340 & 1199.6364 & 2.0 \\
\hline $\mathrm{b}_{11}^{+1}$ & 1328.6766 & 1328.6740 & 2.0 \\
\hline$b_{12}^{+1}$ & 1441.7607 & 1441.7537 & 4.9 \\
\hline $\mathrm{y}_{1}^{+1}$ & 175.1190 & 175.1175 & 8.6 \\
\hline$y_{2}+1$ & 230.1248 & 230.1240 & 3.5 \\
\hline $\mathrm{y}_{5}^{+1}$ & 447.1769 & 447.1748 & 4.7 \\
\hline$y_{6}^{+1}$ & 534.2089 & 534.2072 & 3.2 \\
\hline$y_{7}^{+1}$ & 671.2678 & 671.2626 & 7.7 \\
\hline $\mathrm{y}_{8}^{+1}$ & 743.3081 & 743.3074 & 0.9 \\
\hline $\mathrm{y}_{10}+1$ & 897.3823 & 897.3808 & 1.7 \\
\hline $\mathrm{y}_{11}^{+1}$ & 1000.3915 & 1000.3892 & 2.3 \\
\hline $\mathrm{y}_{12}^{+1}$ & 1087.4236 & 1087.4153 & 7.6 \\
\hline $\mathrm{y}_{13}{ }^{+1}$ & 1158.4607 & 1158.4559 & 4.1 \\
\hline $\mathrm{y}_{14}{ }^{+1}$ & 1272.5036 & 1272.5008 & 2.2 \\
\hline $\mathrm{y}_{15}^{+1}$ & 1385.5877 & 1385.5833 & 3.2 \\
\hline $\mathrm{y}_{16}{ }^{+1}$ & 1484.6561 & 1484.6501 & 4.0 \\
\hline $\mathrm{y}_{10}+2$ & 449.1948 & 449.1926 & 4.9 \\
\hline $\mathrm{y}_{14}^{+2}$ & 636.7554 & 636.7540 & 2.2 \\
\hline $\mathrm{y}_{19}^{+2}$ & 916.9034 & 916.9047 & 1.4 \\
\hline$y_{21}+2$ & 1047.9510 & 1047.9558 & 4.6 \\
\hline$y_{22}{ }^{+2}$ & 1112.4723 & 1112.4755 & 2.9 \\
\hline$y_{26}+2$ & 1354.5990 & 1354.5925 & 4.8 \\
\hline$y_{27}+2$ & 1411.1410 & 1411.1400 & 0.7 \\
\hline $\mathrm{y}_{28}{ }^{+2}$ & 1468.6545 & 1468.6526 & 1.3 \\
\hline$y_{29}{ }^{+2}$ & 1525.1965 & 1525.1906 & 3.9 \\
\hline $\mathrm{y}_{30}+2$ & 1574.7307 & 1574.7313 & 0.4 \\
\hline$y_{31}{ }^{+2}$ & 1638.7600 & 1638.7597 & 0.2 \\
\hline$y_{32}{ }^{+2}$ & 1695.3021 & 1695.2929 & 5.4 \\
\hline$y_{33}+2$ & 1173.2354 & 1173.2272 & 7.0 \\
\hline $\mathrm{MH}-\mathrm{H}_{2} \mathrm{O}^{+3}$ & 1253.9263 & 1253.9334 & 5.7 \\
\hline $\mathrm{MH}-\mathrm{NH}_{3}{ }^{+3}$ & 1254.2543 & 1254.2573 & 2.4 \\
\hline $\mathrm{MH}^{+3}$ & 1259.9298 & 1259.9307 & 4.6 \\
\hline
\end{tabular}

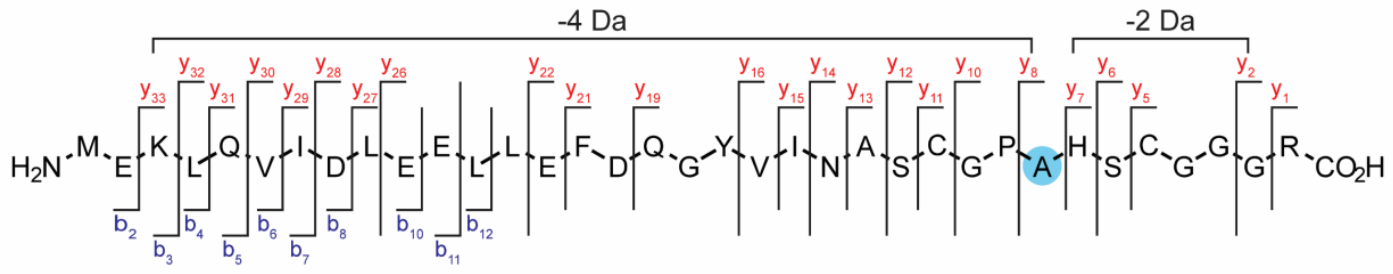


Table S14. HR-MS/MS data for product of GggB reaction with N-Me-A28-GggA substrate. Observed fragments are also indicated in the illustration below the table.

\begin{tabular}{|c|c|c|c|}
\hline Ion & Calc $\mathrm{m} / \mathrm{z}$ & Obs $\mathrm{m} / \mathrm{z}$ & $\Delta p p m$ \\
\hline $\mathrm{b}_{2}^{+1}$ & 261.0904 & 261.0896 & 3.1 \\
\hline $\mathrm{b}_{3}^{+1}$ & 389.1853 & 389.1840 & 3.3 \\
\hline $\mathrm{b}_{4}^{+1}$ & 502.2694 & 502.2676 & 3.6 \\
\hline$b_{5}^{+1}$ & 630.3280 & 630.3268 & 1.9 \\
\hline $\mathrm{b}_{6}^{+1}$ & 729.3964 & 729.3940 & 3.3 \\
\hline $\mathrm{b}_{7}^{+1}$ & 842.4804 & 842.4772 & 3.8 \\
\hline $\mathrm{b}_{8}^{+1}$ & 957.5074 & 957.5039 & 3.7 \\
\hline$b_{9}^{+1}$ & 1070.5914 & 1070.5870 & 4.1 \\
\hline $\mathrm{y}_{1}^{+1}$ & 175.1190 & 175.1173 & 9.7 \\
\hline$y_{2}+1$ & 230.1248 & 230.1239 & 3.9 \\
\hline $\mathrm{y}_{5}^{+1}$ & 447.1769 & 447.1753 & 3.6 \\
\hline $\mathrm{y}_{6}^{+1}$ & 534.2089 & 534.2062 & 5.1 \\
\hline $\mathrm{y}_{7}^{+1}$ & 671.2678 & 671.2644 & 5.1 \\
\hline $\mathrm{y}_{11}^{+1}$ & 1013.4040 & 1013.3993 & 4.6 \\
\hline $\mathrm{y}_{12}{ }^{+1}$ & 1100.4360 & 1100.4282 & 7.1 \\
\hline $\mathrm{y}_{13}{ }^{+1}$ & 1171.4731 & 1171.4679 & 4.4 \\
\hline $\mathrm{y}_{14}^{+1}$ & 1285.5161 & 1285.5102 & 4.6 \\
\hline$y_{15}^{+1}$ & 1398.6001 & 1398.5945 & 4.0 \\
\hline $\mathrm{y}_{16}^{+1}$ & 1497.6685 & 1497.6659 & 1.7 \\
\hline$y_{12}+2$ & 550.7216 & 550.7216 & 0.0 \\
\hline $\mathrm{y}_{14}+2$ & 643.2617 & 643.2588 & 4.5 \\
\hline $\mathrm{y}_{15}+2$ & 699.8037 & 699.8008 & 4.1 \\
\hline $\mathrm{y}_{16}{ }^{+2}$ & 749.3379 & 749.3333 & 6.1 \\
\hline $\mathrm{y}_{18}{ }^{+2}$ & 859.3803 & 859.3813 & 1.2 \\
\hline $\mathrm{y}_{19}{ }^{+2}$ & 923.4096 & 923.4053 & 4.7 \\
\hline$y_{21}{ }^{+2}$ & 1054.4573 & 1054.4558 & 1.4 \\
\hline$y_{22}+2$ & 1118.9786 & 1118.9734 & 4.6 \\
\hline$y_{23}+2$ & 1175.5206 & 1175.5194 & 1.0 \\
\hline$y_{26}^{+2}$ & 1361.1052 & 1361.1051 & 0.1 \\
\hline$y_{27}^{+2}$ & 1417.6473 & 1417.6393 & 5.6 \\
\hline $\mathrm{y}_{28}^{+2}$ & 1475.1607 & 1475.1564 & 2.9 \\
\hline $\mathrm{y}_{29}{ }^{+2}$ & 1531.7028 & 1531.6993 & 2.3 \\
\hline $\mathrm{y}_{30}{ }^{+2}$ & 1581.2370 & 1581.2304 & 4.2 \\
\hline$y_{31}{ }^{+2}$ & 1645.2663 & 1645.2635 & 1.7 \\
\hline $\mathrm{y}_{32}+2$ & 1701.8083 & 1701.8001 & 4.8 \\
\hline$y_{33}+3$ & 1177.5729 & 1177.5683 & 3.9 \\
\hline $\mathrm{MH}-\mathrm{H}_{2} \mathrm{O}^{+3}$ & 1258.2638 & 1258.2581 & 4.5 \\
\hline $\mathrm{MH}-\mathrm{NH}_{3}{ }^{+3}$ & 1258.5918 & 1258.5917 & 0.1 \\
\hline $\mathrm{MH}^{+3}$ & 1264.2673 & 1264.2656 & 1.3 \\
\hline
\end{tabular}

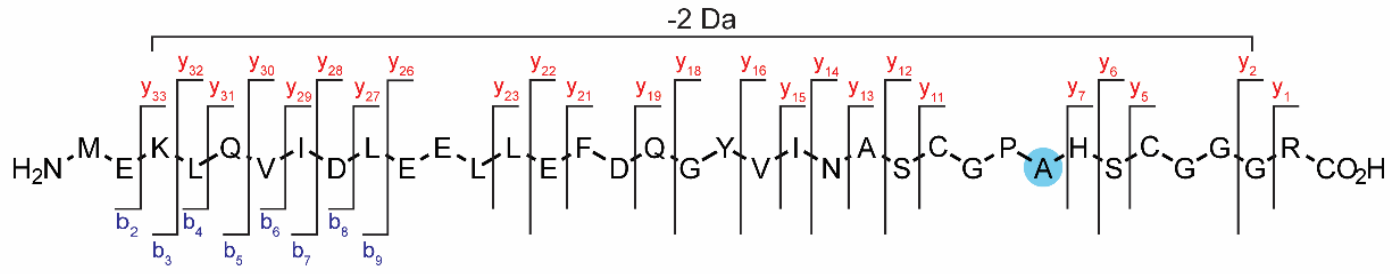


Table S15. HR-MS data for HRV-3C-cleaved GggA variants.

\begin{tabular}{ccccc}
\hline & Ion & Calc & Obs & $\Delta p p m$ \\
\hline $3 x$ & {$[\mathrm{M}+4 \mathrm{H}]^{3+}$} & 1208.05073 & 1208.06818 & 14.4 \\
& {$[\mathrm{M}+5 \mathrm{H}]^{5+}$} & 966.64204 & 966.65660 & 15.1 \\
\hline \multirow{3}{*}{$4 \mathrm{x}$} & {$[\mathrm{M}+4 \mathrm{H}]^{4+}$} & 1336.84849 & 1336.86470 & 12.1 \\
& {$[\mathrm{M}+5 \mathrm{H}]^{5+}$} & 1069.68025 & 1069.69238 & 11.3 \\
& {$[\mathrm{M}+6 \mathrm{H}]^{6+}$} & 891.56809 & 891.57922 & 12.5 \\
\hline
\end{tabular}

Table S16. HR-MS data for AspN-cleaved GggA variants.

\begin{tabular}{ccccc}
\hline & Ion & Calc & Obs & $\Delta$ ppm \\
\hline \multirow{2}{*}{ wildtype } & {$[\mathrm{M}+2 \mathrm{H}]^{2+}$} & 980.90487 & 980.90955 & 4.8 \\
& {$[\mathrm{M}+3 \mathrm{H}]^{3+}$} & 654.27234 & 654.27574 & 5.2 \\
\hline $1 \mathrm{x}$ & {$[\mathrm{M}+1 \mathrm{H}]^{1+}$} & 1394.61174 & 1394.59625 & 11.1 \\
& {$[\mathrm{M}+2 \mathrm{H}]^{2+}$} & 697.80951 & 697.80376 & 8.2 \\
\hline $2 \mathrm{x}$ & {$[\mathrm{M}+2 \mathrm{H}]^{2+}$} & 955.40504 & 955.40190 & 3.3 \\
& {$[\mathrm{M}+3 \mathrm{H}]^{3+}$} & 637.27245 & 637.27150 & 1.5 \\
\hline $3 \mathrm{x}$ & {$[\mathrm{M}+3 \mathrm{H}]^{3+}$} & 809.00281 & 809.00215 & 0.8 \\
\hline \multirow{2}{*}{$4 \mathrm{x}$} & {$[\mathrm{M}+3 \mathrm{H}]^{3+}$} & 980.73316 & 980.73533 & 2.2 \\
& {$[\mathrm{M}+4 \mathrm{H}]^{3+}$} & 735.80169 & 735.80598 & 5.8 \\
\hline
\end{tabular}


Table S17. HR-MS/MS data for AspN-cleaved wt GggA. Observed fragments are also indicated in the illustration below the table.

\begin{tabular}{cccc}
\hline Ion & Calc $\mathrm{m} / \mathrm{z}$ & Obs $\mathrm{m} / \mathrm{z}$ & $\Delta \mathrm{ppm}$ \\
\hline $\mathrm{b}_{2}{ }^{+1}$ & 244.0928 & 244.0927 & 0.4 \\
$\mathrm{~b}_{3}{ }^{+1}$ & 301.1143 & 301.1149 & 2.0 \\
$\mathrm{~b}_{4}{ }^{+1}$ & 464.1776 & 464.1784 & 1.7 \\
$\mathrm{~b}_{5}{ }^{+1}$ & 563.2460 & 563.2463 & 0.5 \\
$\mathrm{~b}_{6}{ }^{+1}$ & 676.3301 & 676.3287 & 2.1 \\
$\mathrm{~b}_{7}{ }^{+1}$ & 790.3730 & 790.3686 & 5.6 \\
$\mathrm{~b}_{8}{ }^{+1}$ & 861.4101 & 861.4111 & 1.2 \\
\hline $\mathrm{y}_{1}{ }^{+1}$ & 175.1190 & 175.1186 & 2.3 \\
$\mathrm{y}_{2}{ }^{+1}$ & 230.1248 & 230.1250 & 0.9 \\
$\mathrm{y}_{6}{ }^{+1}$ & 534.2089 & 534.2112 & 4.3 \\
$\mathrm{y}_{7}{ }^{+1}$ & 671.2678 & 671.2694 & 2.4 \\
$\mathrm{y}_{8}{ }^{+1}$ & 756.2842 & 756.2866 & 3.2 \\
$\mathrm{y}_{9}{ }^{+1}$ & 853.3370 & 853.3389 & 2.2 \\
$\mathrm{y}_{10}{ }^{+1}$ & 910.3584 & 910.3556 & 3.1 \\
$\mathrm{y}_{11}{ }^{+1}$ & 1013.3676 & 1013.3677 & 0.1 \\
$\mathrm{y}_{12}{ }^{+1}$ & 1100.3996 & 1100.4006 & 0.9 \\
$\mathrm{y}_{13}{ }^{+1}$ & 1171.4368 & 1171.4381 & 1.1 \\
$\mathrm{y}_{14}{ }^{+1}$ & 1285.4797 & 1285.4812 & 1.2 \\
$\mathrm{y}_{15}{ }^{+1}$ & 1398.5637 & 1398.5651 & 1.0 \\
$\mathrm{y}_{16}{ }^{+1}$ & 1497.6322 & 1497.6378 & 3.7 \\
$\mathrm{y}_{15}{ }^{+2}$ & 699.7855 & 699.7866 & 1.6 \\
$\mathrm{y}_{16}{ }^{+2}$ & 749.3197 & 749.3190 & 0.9 \\
$\mathrm{y}_{18}{ }^{+2}$ & 859.3621 & 859.3626 & 0.6 \\
$\mathrm{y}_{19}{ }^{+2}$ & 923.3914 & 923.3912 & 0.2 \\
\hline $\mathrm{MH}{ }^{+\mathrm{H} 2 \mathrm{O}^{+2}}$ & 971.8996 & 971.9027 & 3.2 \\
$\mathrm{MH}^{+2}$ & 980.9049 & 980.9084 & 3.6 \\
\hline & & &
\end{tabular}

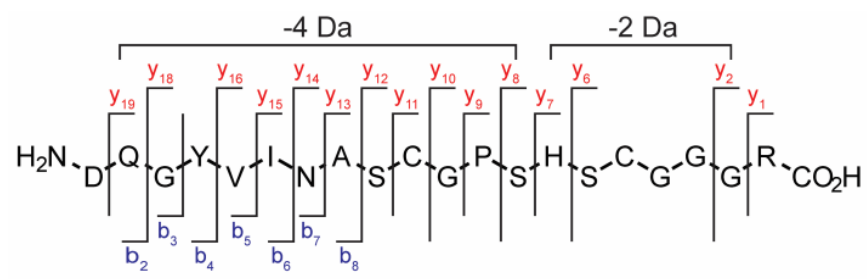


Table S18. HR-MS/MS data for AspN-cleaved GggA-1xSCGGGR. Observed fragments are also indicated in the illustration below the table.

\begin{tabular}{cccc}
\hline Ion & Calc $\mathrm{m} / \mathrm{z}$ & Obs $\mathrm{m} / \mathrm{z}$ & $\Delta \mathrm{ppm}$ \\
\hline $\mathrm{b}_{2}{ }^{+1}$ & 244.0928 & 244.0916 & 4.9 \\
$\mathrm{~b}_{3}{ }^{+1}$ & 301.1143 & 301.1125 & 6.0 \\
$\mathrm{~b}_{4}{ }^{+1}$ & 464.1776 & 464.1726 & 10.8 \\
$\mathrm{~b}_{5}{ }^{+1}$ & 563.2460 & 563.2451 & 1.6 \\
\hline $\mathrm{y}_{1}{ }^{+1}$ & 175.1190 & 175.1191 & 0.6 \\
$\mathrm{y}_{2}{ }^{+1}$ & 230.1248 & 230.1212 & 15.6 \\
$\mathrm{y}_{5}{ }^{+1}$ & 447.1769 & 447.1791 & 4.9 \\
$\mathrm{y}_{6}{ }^{+1}$ & 534.2089 & 534.2013 & 14.2 \\
$\mathrm{y}_{7}{ }^{+1}$ & 605.2460 & 605.2421 & 6.4 \\
$\mathrm{y}_{8}{ }^{+1}$ & 719.2889 & 719.2879 & 1.4 \\
$\mathrm{y}_{9}{ }^{+1}$ & 832.3730 & 832.3657 & 8.8 \\
$\mathrm{y}_{11}{ }^{+1}$ & 931.4414 & 931.4366 & 5.2 \\
$\mathrm{y}_{12}{ }^{+1}$ & 1094.5048 & 1094.5112 & 5.8 \\
\hline $\mathrm{MH}^{+2}$ & 1151.5262 & 1151.5153 & 9.5 \\
\hline
\end{tabular}

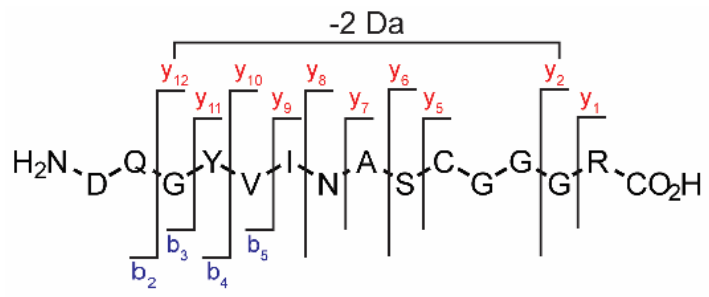


Table S19. HR-MS/MS data for AspN-cleaved GggA-2xSCGGGR. Observed fragments are also indicated in the illustration below the table.

\begin{tabular}{cccc}
\hline Ion & Calc $\mathrm{m} / \mathrm{z}$ & Obs $\mathrm{m} / \mathrm{z}$ & $\Delta \mathrm{ppm}$ \\
\hline $\mathrm{b}_{2}{ }^{+1}$ & 244.0928 & 244.0889 & 16.0 \\
$\mathrm{~b}_{3}{ }^{+1}$ & 301.1143 & 301.1095 & 15.9 \\
$\mathrm{~b}_{4}{ }^{+1}$ & 464.1776 & 464.1701 & 16.2 \\
$\mathrm{~b}_{5}{ }^{+1}$ & 563.2460 & 563.2366 & 16.7 \\
$\mathrm{~b}_{8}{ }^{+1}$ & 861.4101 & 861.3963 & 16.0 \\
\hline $\mathrm{y}_{1}{ }^{+1}$ & 175.1190 & 175.1160 & 17.1 \\
$\mathrm{y}_{2}{ }^{+1}$ & 230.1248 & 230.1212 & 15.6 \\
$\mathrm{y}_{6}{ }^{+1}$ & 534.2089 & 534.2013 & 14.2 \\
$\mathrm{y}_{8}{ }^{+1}$ & 745.3158 & 745.3051 & 14.4 \\
$\mathrm{y}_{13}{ }^{+2}$ & 560.7222 & 560.7142 & 14.3 \\
$\mathrm{y}_{14}{ }^{+2}$ & 617.7436 & 617.7341 & 15.4 \\
$\mathrm{y}_{15}{ }^{+2}$ & 674.2857 & 674.2767 & 13.3 \\
$\mathrm{y}_{16}{ }^{+2}$ & 723.8199 & 723.8083 & 16.0 \\
$\mathrm{y}_{17}{ }^{+2}$ & 805.3515 & 805.3364 & 18.7 \\
$\mathrm{y}_{18}{ }^{+2}$ & 833.8623 & 833.8488 & 16.2 \\
$\mathrm{y}_{19}{ }^{+2}$ & 897.8916 & 897.8795 & 13.5 \\
\hline $\mathrm{MH} \mathrm{H}_{2} \mathrm{O}^{+2}$ & 946.3998 & 946.3869 & 13.6 \\
$\mathrm{MH}^{+2}$ & 955.4050 & 955.3924 & 13.2 \\
\hline
\end{tabular}

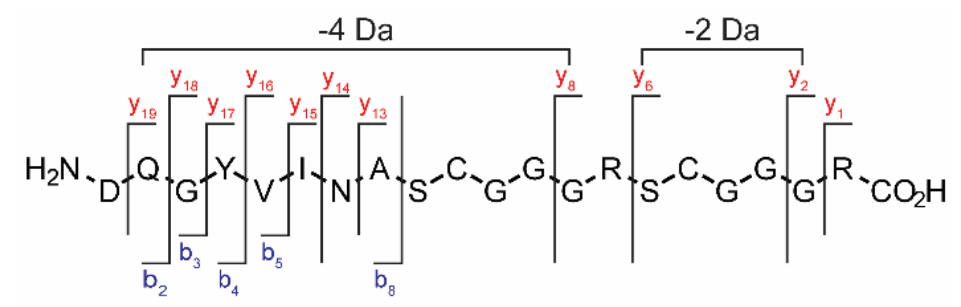


Table S20. HR-MS/MS data for AspN-cleaved GggA-3xSCGGGR. Observed fragments are also indicated in the illustration below the table.

\begin{tabular}{cccc}
\hline Ion & Calc m/z & Obs m/z & $\Delta$ ppm \\
\hline $\mathrm{b}_{2}{ }^{+1}$ & 244.0928 & 244.0908 & 8.2 \\
$\mathrm{~b}_{3}{ }^{+1}$ & 301.1143 & 301.1119 & 8.0 \\
$\mathrm{~b}_{4}{ }^{+1}$ & 464.1776 & 464.1744 & 6.9 \\
$\mathrm{~b}_{5}{ }^{+1}$ & 563.2460 & 563.2414 & 8.2 \\
\hline $\mathrm{y}_{1}{ }^{+1}$ & 175.1190 & 175.1171 & 10.8 \\
$\mathrm{y}_{2}{ }^{+1}$ & 230.1248 & 230.1216 & 13.9 \\
$\mathrm{y}_{6}-\mathrm{H}_{2} \mathrm{O}$ & 516.1983 & 516.1920 & 12.2 \\
$\mathrm{y}_{6}{ }^{+1}$ & 534.2089 & 534.2089 & 0.0 \\
$\mathrm{y}_{8}-\mathrm{NH}_{3}$ & 728.2893 & 728.2937 & 6.0 \\
$\mathrm{y}_{12}-\mathrm{H}_{2} \mathrm{O}$ & 1031.3894 & 1031.3728 & 16.1 \\
$\mathrm{y}_{14}-\mathrm{NH}_{3}{ }^{+2}$ & 622.2438 & 622.2394 & 7.1 \\
$\mathrm{y}_{18}-\mathrm{NH}_{3}{ }^{+2}$ & 774.2859 & 774.2882 & 3.0 \\
$\mathrm{y}_{19}-\mathrm{NH}_{3}{ }^{+2}$ & 809.8044 & 809.7959 & 10.5 \\
$\mathrm{y}_{20}-\mathrm{NH}_{3}{ }^{+2}$ & 866.8259 & 866.8202 & 6.6 \\
$\mathrm{y}_{20}{ }^{+2}$ & 875.3392 & 875.3477 & 9.7 \\
$\mathrm{y}_{21}{ }^{+2}$ & 931.8812 & 931.8662 & 16.1 \\
$\mathrm{y}_{22}-\mathrm{NH}_{3}{ }^{+2}$ & 972.9021 & 972.8916 & 10.8 \\
$\mathrm{y}_{23}{ }^{+3}$ & 708.9671 & 708.9626 & 6.3 \\
$\mathrm{y}_{24}-\mathrm{NH}_{3}{ }^{+2}$ & 1082.9445 & 1082.9361 & 7.8 \\
$\mathrm{y}_{25}-\mathrm{NH}_{3}{ }^{+3}$ & 764.9850 & 764.9887 & 4.8 \\
$\mathrm{y}_{25}{ }^{+3}$ & 770.6605 & 770.6528 & 10.0 \\
\hline${\mathrm{MH}-\mathrm{NH}_{3}{ }^{+3}}^{\mathrm{MH}^{+3}}$ & 803.3273 & 803.3236 & 4.6 \\
\hline & 809.0028 & 808.9991 & 4.6 \\
\hline
\end{tabular}

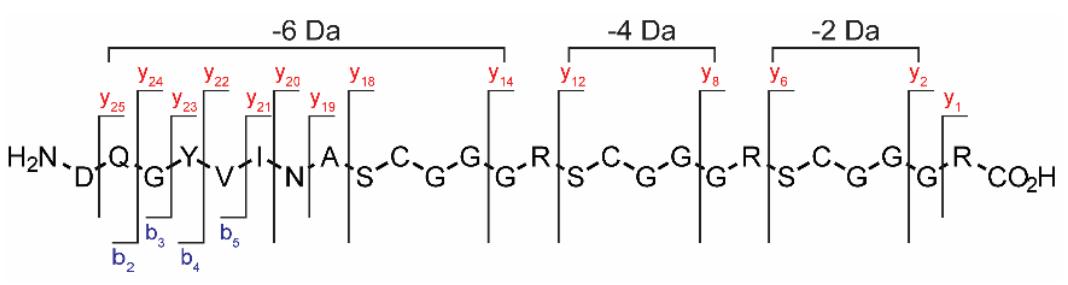


Table S21. HR-MS/MS data for AspN-cleaved GggA-4xSCGGGR. Observed fragments are also indicated in the illustration below the table.

\begin{tabular}{cccc}
\hline Ion & Calc $\mathrm{m} / \mathrm{z}$ & Obs m/z & $\Delta \mathrm{ppm}$ \\
\hline $\mathrm{b}_{2}{ }^{+1}$ & 244.0928 & 244.0936 & 3.3 \\
$\mathrm{~b}_{3}{ }^{+1}$ & 301.1143 & 301.1141 & 0.7 \\
$\mathrm{~b}_{4}{ }^{+1}$ & 464.1776 & 464.1705 & 15.3 \\
\hline $\mathrm{y}_{1}{ }^{+1}$ & 175.1190 & 175.1177 & 7.4 \\
$\mathrm{y}_{2}{ }^{+1}$ & 230.1248 & 230.1234 & 6.1 \\
$\mathrm{y}_{6}-\mathrm{H}_{2} \mathrm{O}$ & 516.1983 & 516.1985 & 0.4 \\
$\mathrm{y}_{14}-\mathrm{NH}_{3}{ }^{+2}$ & 622.2438 & 622.2395 & 6.9 \\
$\mathrm{y}_{18}-\mathrm{NH}_{3}{ }^{+2}$ & 774.2859 & 774.2982 & 15.9 \\
\hline $\mathrm{MH}-\mathrm{H}_{2} \mathrm{O}^{+3}$ & 974.7296 & 974.7316 & 2.1 \\
\hline
\end{tabular}

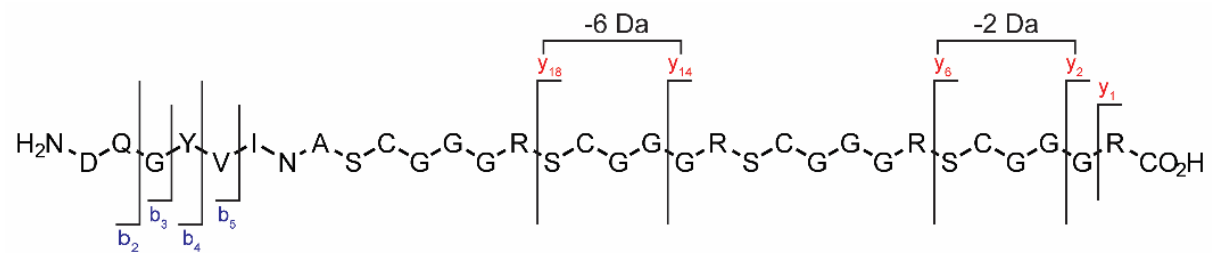

Table S22. HR-MS/MS data for HRV-3C-cleaved GggA-3xSCGGGR, C31S. Observed fragments are also indicated in the illustration below the table.

\begin{tabular}{cccc}
\hline lon & Calc $\mathrm{m} / \mathrm{z}$ & Obs $\mathrm{m} / \mathrm{z}$ & $\Delta \mathrm{ppm}$ \\
\hline $\mathrm{b}_{2}{ }^{+1}$ & 155.0815 & 155.0583 & \\
$\mathrm{~b}_{3}{ }^{+1}$ & 284.1241 & 284.1234 & \\
$\mathrm{~b}_{4}{ }^{+1}$ & 431.1925 & 431.1990 & \\
$\mathrm{~b}_{5}{ }^{+1}$ & 488.2140 & 488.2177 & \\
\hline $\mathrm{y}_{1}{ }^{+1}$ & 175.1190 & 175.1010 & \\
$\mathrm{y}_{2}{ }^{+1}$ & 230.1248 & 230.1174 & \\
$\mathrm{y}_{6}-\mathrm{H}_{2} \mathrm{O}$ & 516.1983 & 516.2057 & \\
$\mathrm{y}_{6}{ }^{+1}$ & 534.2089 & 534.2078 & \\
$\mathrm{y}_{7}{ }^{+2}$ & 345.6586 & 345.6617 & \\
$\mathrm{y}_{8}{ }^{+2}$ & 374.1694 & 374.1683 & \\
\hline
\end{tabular}

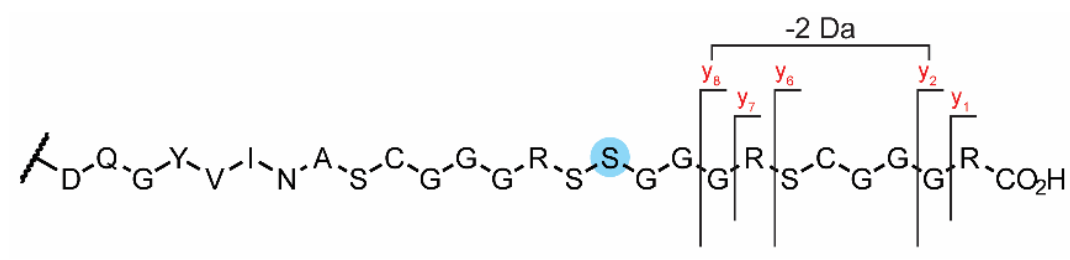


Table S23. HR-MS/MS data for streptosactin identified in S. thermophilus JIM 8232 cultures. Observed fragments are also indicated in the illustration below the table.

\begin{tabular}{cccc}
\hline Ion & Calc $\mathrm{m} / \mathrm{z}$ & Obs $\mathrm{m} / \mathrm{z}$ & $\Delta \mathrm{ppm}$ \\
\hline $\mathrm{b}_{2}{ }^{+1}$ & 186.0873 & 186.0866 & 3.8 \\
\hline $\mathrm{y}_{1}{ }^{+1}$ & 175.1190 & 175.1184 & 3.4 \\
$\mathrm{y}_{2}{ }^{+1}$ & 230.1248 & 230.1257 & 3.9 \\
$\mathrm{y}_{6}{ }^{+1}$ & 534.2089 & 534.2100 & 2.1 \\
$\mathrm{y}_{7}{ }^{+1}$ & 671.2678 & 671.2675 & 0.4 \\
$\mathrm{y}_{8}{ }^{+1}$ & 756.2842 & 756.2805 & 4.9 \\
$\mathrm{y}_{9}{ }^{+1}$ & 853.3370 & 853.3372 & 0.2 \\
$\mathrm{y}_{10}{ }^{+1}$ & 910.3584 & 910.3519 & 7.1 \\
$\mathrm{y}_{11}{ }^{+1}$ & 1013.3676 & 1013.3637 & 3.8 \\
$\mathrm{y}_{12}{ }^{+1}$ & 1100.3996 & 1100.4032 & 3.3 \\
\hline
\end{tabular}

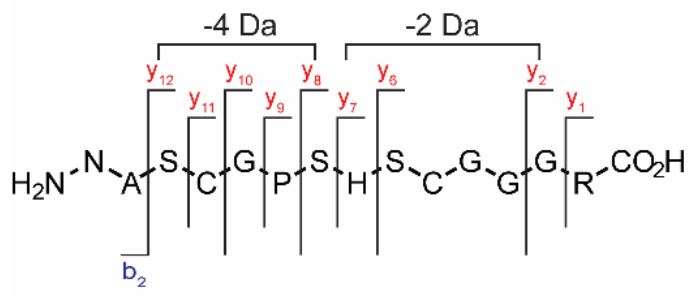

Table S24. HR-MS data for the products of protease cleavage reactions in the synthesis of streptosactin.

\begin{tabular}{ccccc}
\hline & Ion & Calc & Obs & $\Delta$ ppm \\
\hline \multirow{4}{*}{ HRV-3C } & {$[\mathrm{M}+3 \mathrm{H}]^{3+}$} & 1507.70178 & 1507.70255 & 0.5 \\
& {$[\mathrm{M}+4 \mathrm{H}]^{4+}$} & 1131.02816 & 1131.03090 & 2.4 \\
& {$[\mathrm{M}+5 \mathrm{H}]^{5+}$} & 905.02398 & 905.02680 & 3.1 \\
& {$[\mathrm{M}+6 \mathrm{H}]^{5+}$} & 754.35453 & 754.35866 & 5.5 \\
\hline \multirow{3}{*}{ AspN } & {$[\mathrm{M}+2 \mathrm{H}]^{2+}$} & 1058.95543 & 1058.95226 & 3.0 \\
& {$[\mathrm{M}+3 \mathrm{H}]^{3+}$} & 706.30604 & 706.30446 & 2.2 \\
& {$[\mathrm{M}+4 \mathrm{H}]^{4+}$} & 529.98135 & 529.98194 & 1.1 \\
\hline \multirow{3}{*}{ Trypsin } & {$[\mathrm{M}+1 \mathrm{H}]^{1+}$} & 1285.47968 & 1285.47931 & 0.3 \\
& {$[\mathrm{M}+2 \mathrm{H}]^{2+}$} & 643.24348 & 643.24405 & 0.9 \\
& {$[\mathrm{M}+3 \mathrm{H}]^{3+}$} & 429.16474 & 429.16543 & 1.6 \\
\hline
\end{tabular}


Table S25. HR-MS/MS data for synthetic streptosactin. Observed fragments are also indicated in the illustration below the table.

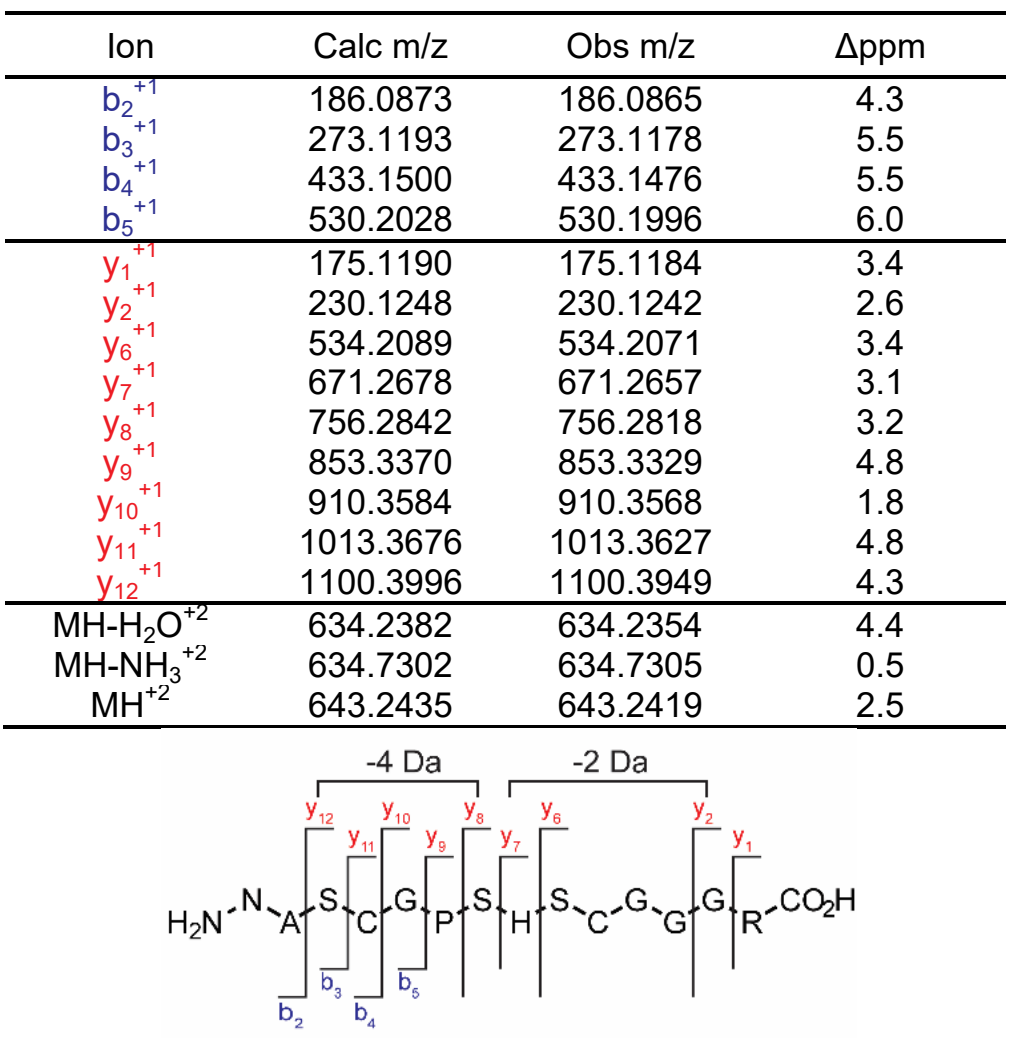

Table S26. Bacterial strains used to assess the effect of streptosactin.

\begin{tabular}{c|l|c}
\hline Strain & Description & $\begin{array}{c}\text { SI } \\
\text { Reference }\end{array}$ \\
\hline A909 & Streptococcus agalactiae A909 wild-type isolate & 6 \\
\hline ATCC 10556 & $\begin{array}{l}\text { Streptococcus sanguinis ATCC 10556 wild-type isolate, } \\
\text { also known as SK1 }\end{array}$ & ATCC \\
\hline ATCC 11454 & Lactococcus lactis ATCC 11454 wild-type isolate & ATCC \\
\hline CCUG 31611 & $\begin{array}{l}\text { Streptococcus mitis CCUG 31611 wild-type isolate, also } \\
\text { known as NCTC 12261 }\end{array}$ & 7 \\
\hline DSM 20646 & Streptococcus ferus DSM 20646 wild-type isolate & 8 \\
\hline JB1 & Streptococcus bovis JB1 wild-type isolate & 9 \\
\hline LMD-9 & Streptococcus thermophilus LMD-9 wild-type isolate & ATCC \\
\hline LMG 18311 & Streptococcus thermophilus LMG 18311 wild-type isolate & ATCC \\
\hline NZ131 & Streptococcus pyogenes NZ131 wild-type isolate & 5 \\
\hline S. iniae 9066 & Streptococcus gordonii Challis wild-type isolate & 10 \\
\hline SL1 & Streptococcus iniae 9066 wild-type isolate, from M. Neely & 11 \\
\hline S. oralis 108 & $\begin{array}{l}\text { Streptococcus sobrinus SL1 wild-type isolate, also known } \\
\text { as ATCC 33478 }\end{array}$ & ATCC \\
\hline UA159 & Streptococcus oralis 108 wild-type isolate, from L. Tao & 12 \\
\hline V583 & Streptococcus mutans UA159 wild-type isolate & 13 \\
\hline & Enterococcus faecalis V583 wild-type isolate & 14 \\
\hline
\end{tabular}


Figure S1. Alignment of the SPASM domains of SuiB and GggB. ${ }^{15}$ Cys residues that ligate the Aux-I and Aux-II Fe-S clusters are shown in red and blue, respectively.

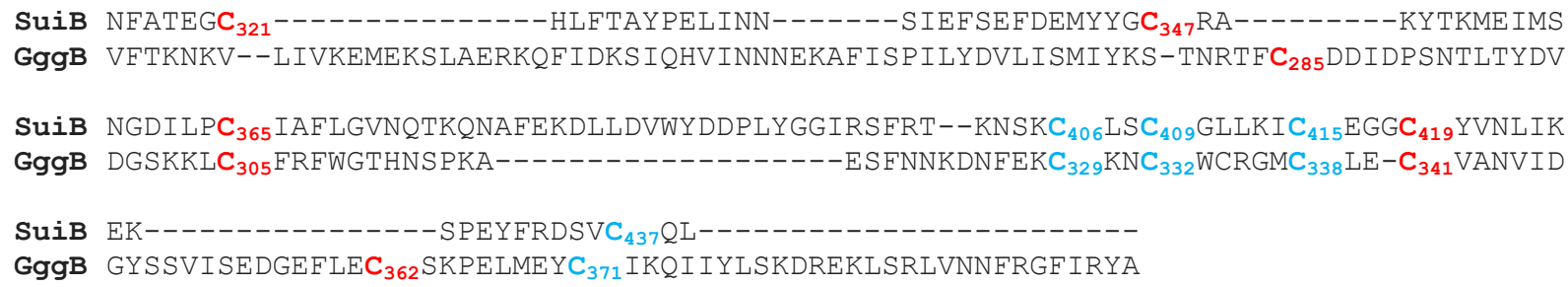

Figure S2. ${ }^{13} \mathrm{C}$ NMR spectra of ${ }^{13} \mathrm{C}_{2},{ }^{15} \mathrm{~N}_{1}-\mathrm{G} 34$-GggA before (top) and after (bottom) reaction with GggB.
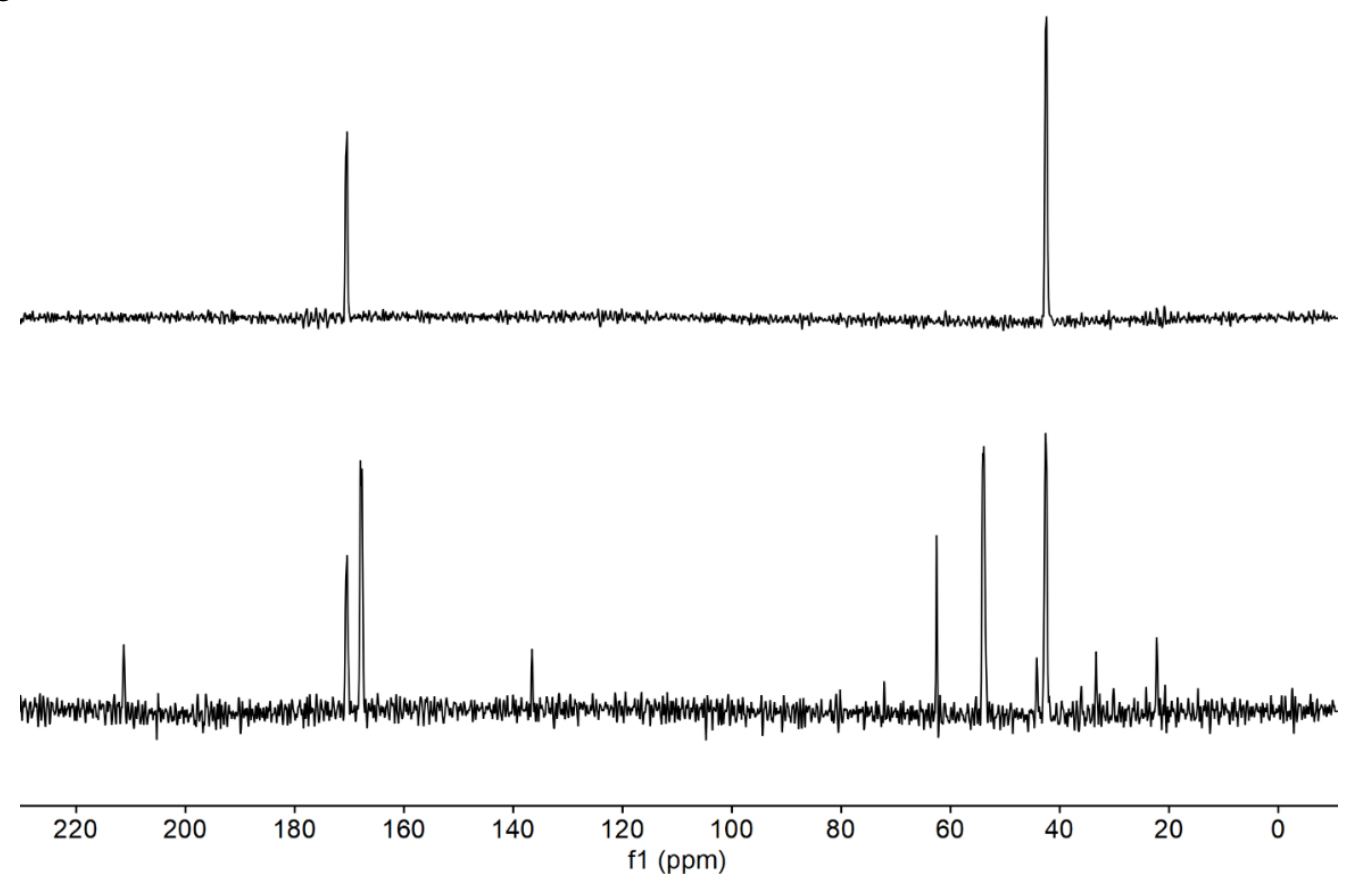
Figure S3. HSQC spectrum of ${ }^{13} \mathrm{C}_{2},{ }^{15} \mathrm{~N}_{1}-\mathrm{G} 34-\mathrm{GggA}$ after reaction with GggB. Key correlations are indicated with boxes and labeled.

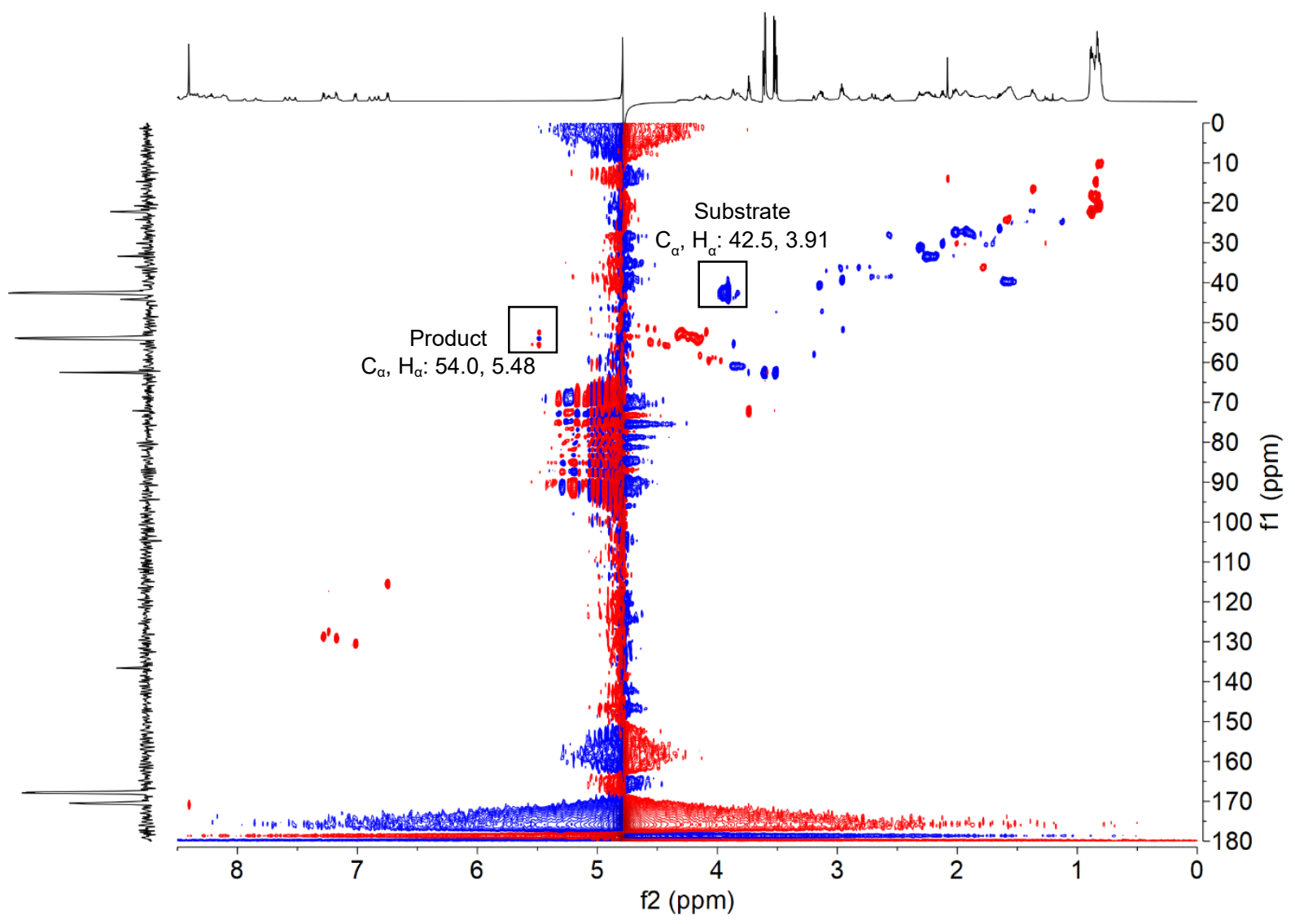


Figure S4. ${ }^{13} \mathrm{C}$ NMR spectra of ${ }^{13} \mathrm{C}_{3}-\mathrm{A} 28-\mathrm{GggA}$ before (top) and after (bottom) reaction with GggB.
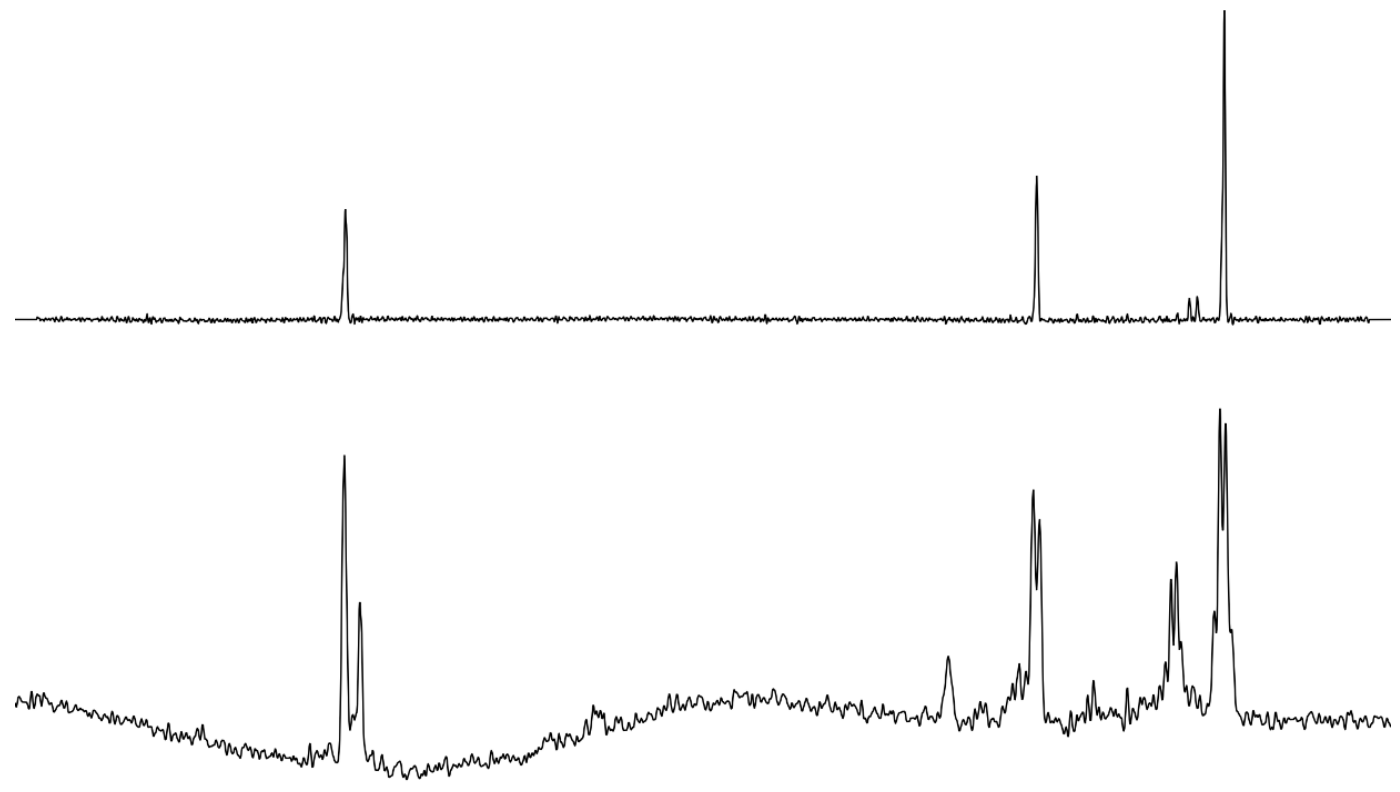

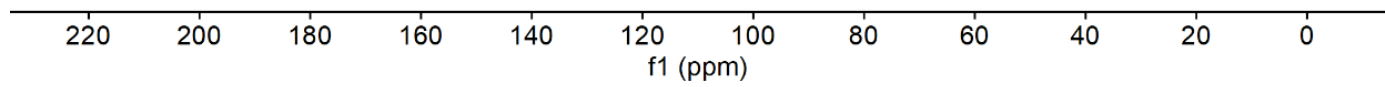

Figure S5. HSQC spectrum of ${ }^{13} \mathrm{C}_{2},{ }^{15} \mathrm{~N}_{1}-\mathrm{G} 34-\mathrm{GggA}$ after reaction with GggB. Key correlations are indicated with boxes and labeled.

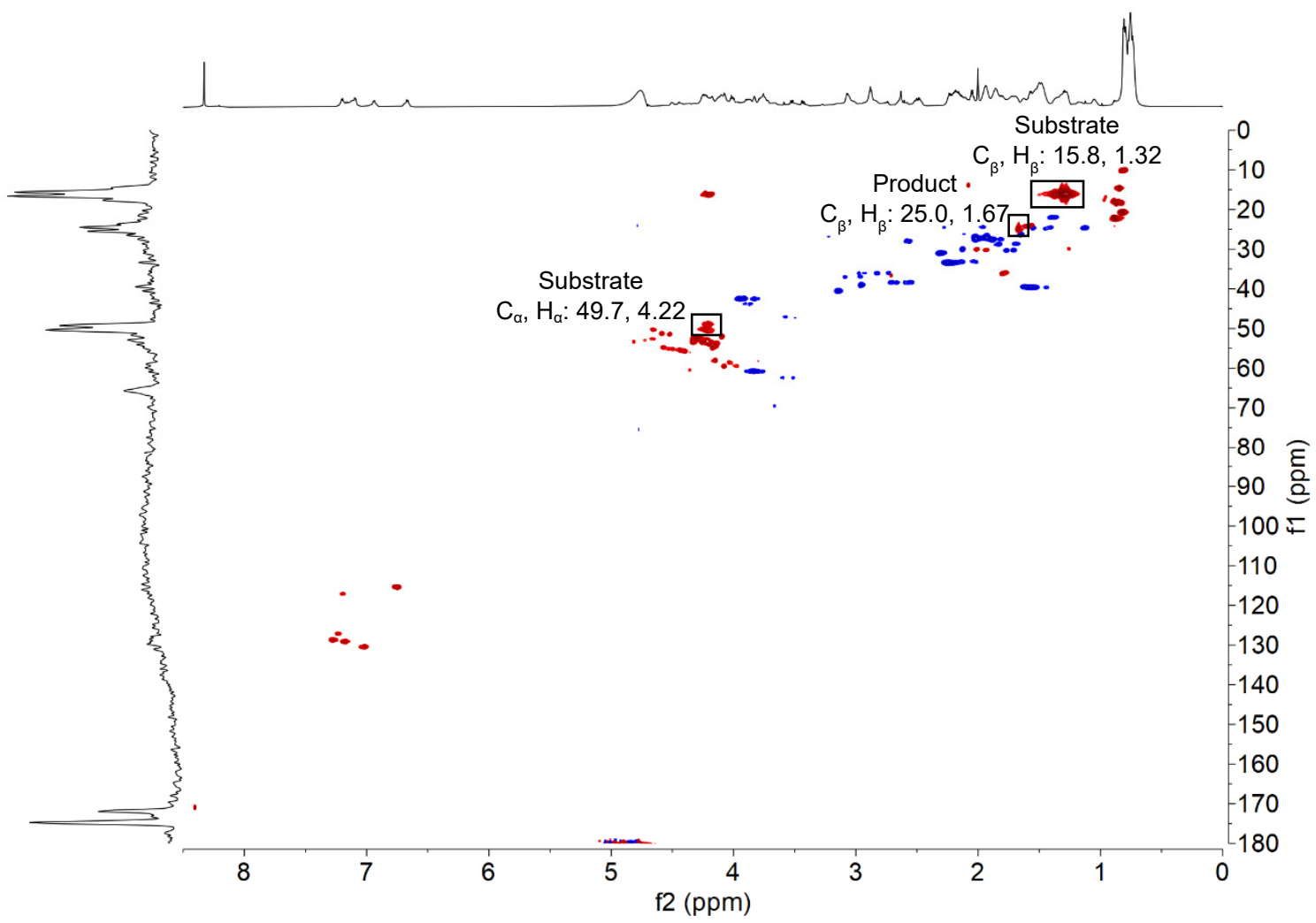


Figure S6. Proposed reaction mechanisms for GggB. Shown are a homolytic mechanism (a) for C-S bond formation and two heterolytic mechanisms (b, c).

a
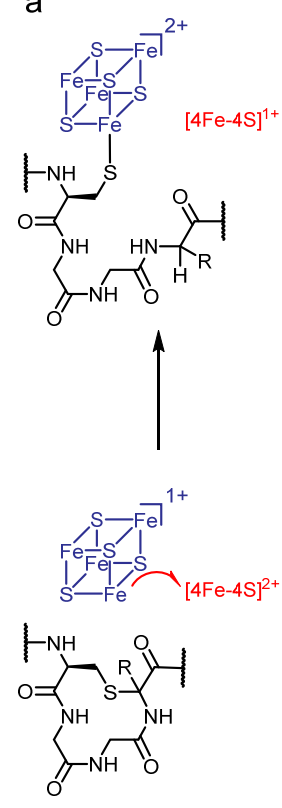

b

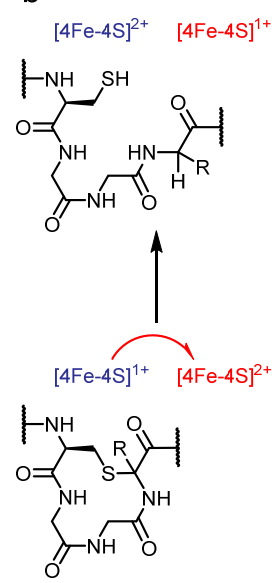

C

$[4 \mathrm{Fe}-4 \mathrm{~S}]^{2+}[4 \mathrm{Fe}-4 \mathrm{~S}]^{1+}$<smiles>[R]C([R])(CC)C(=O)NC(=O)CNC(=O)CNC(=O)C(CS)NC(C)C</smiles>

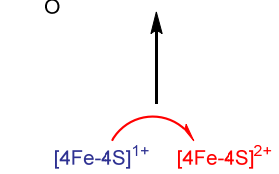

$\sum_{\mathrm{O}}^{\mathrm{NH}}$
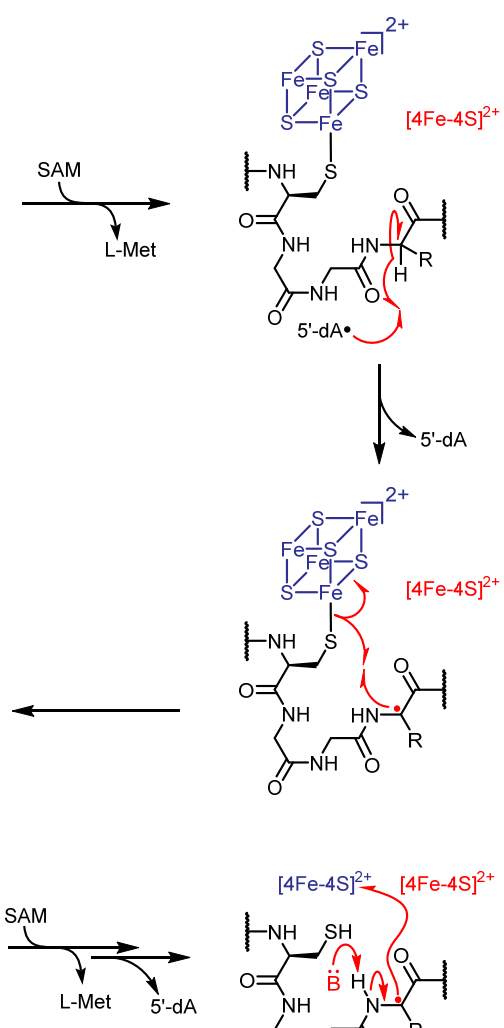

$[4 \mathrm{Fe}-4 \mathrm{~S}]^{2+}+[4 \mathrm{Fe}-4 \mathrm{~S}]^{2+}$
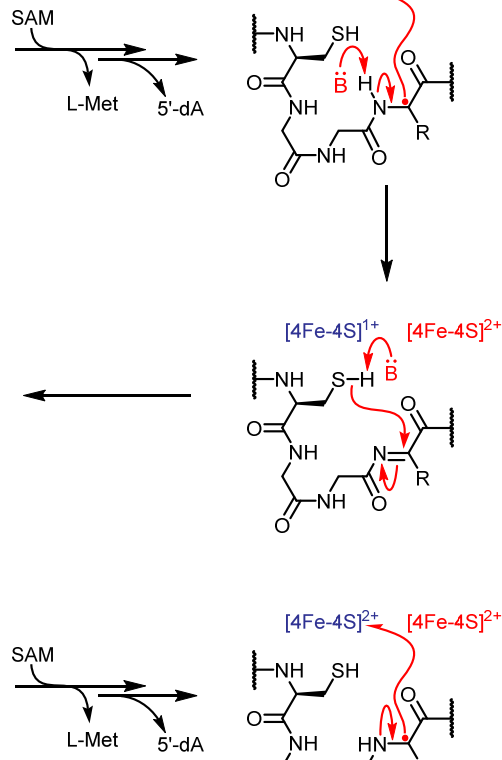

$[4 \mathrm{Fe}-4 \mathrm{~S}]^{2+}[4 \mathrm{Fe}-4 \mathrm{~S}]^{2+}$
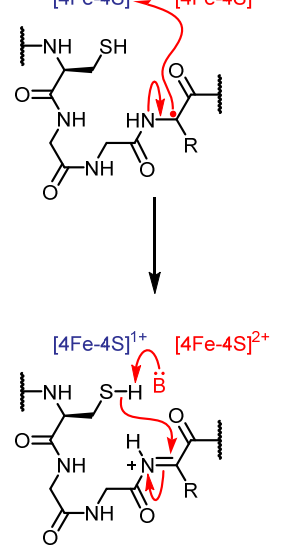
Figure S7. HR-MS spectra of 5'-deoxyadenosine produced in the reaction of GggB with (a) no peptide, (b) wt GggA (unlabeled), (c) $\alpha-{ }^{2} \mathrm{H}_{2}-\mathrm{G} 34-\mathrm{GggA}$, and (d) $\alpha-{ }^{2} \mathrm{H}_{1}-\mathrm{A} 28-\mathrm{GggA}$. An increase in the percent abundance of the second and third isotope peaks in (c) and (d) is indicative of the presence of $5-{ }^{2} \mathrm{H}-5^{\prime}-\mathrm{dA}$. $5-{ }^{1} \mathrm{H}-5^{\prime}-\mathrm{dA}$ is also present due to futile SAM cleavage.
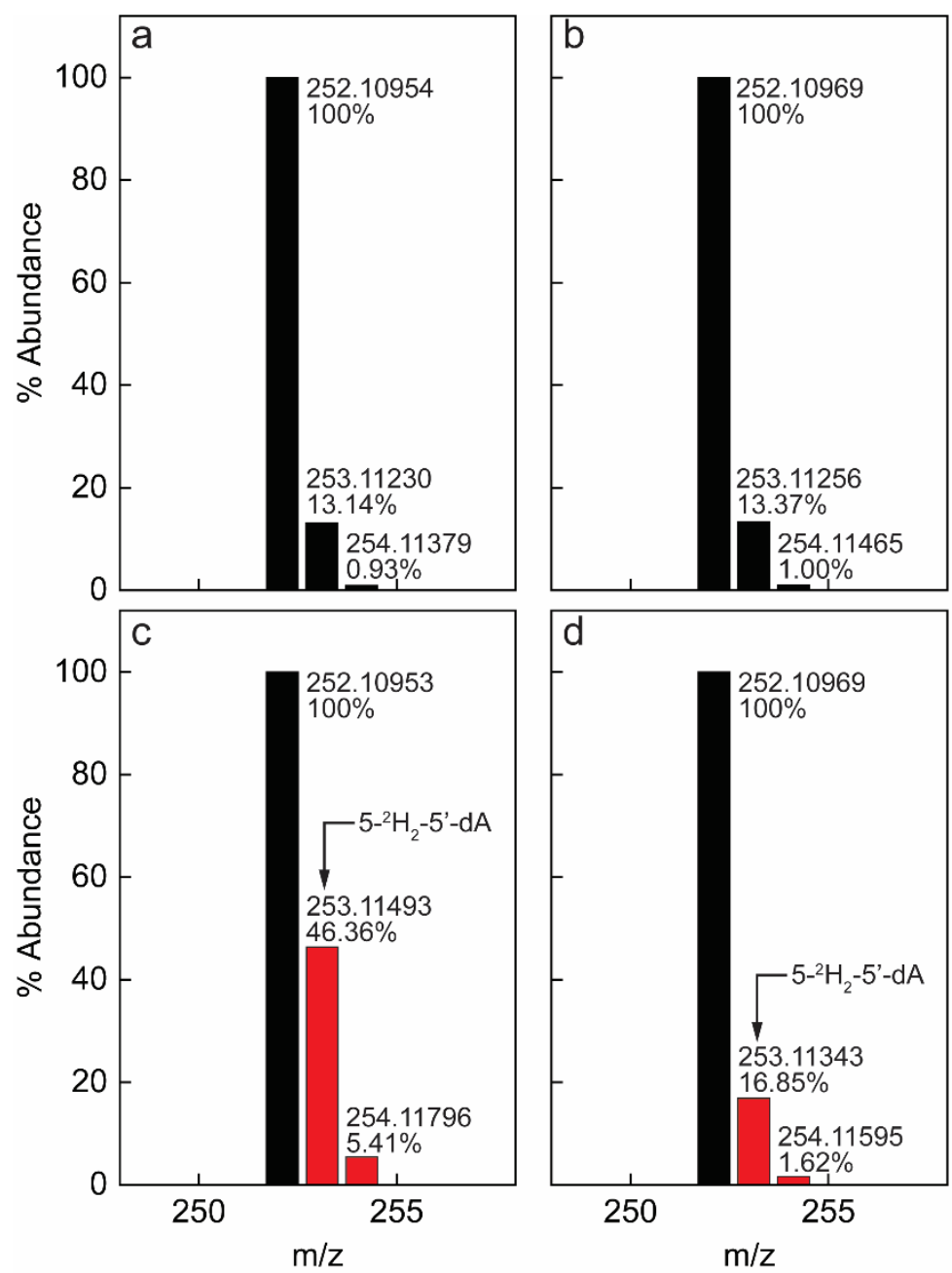
Figure S8. NMR spectra of synthetic streptosactin in $\mathrm{D}_{2} \mathrm{O}$. Shown are in order: ${ }^{1} \mathrm{H},{ }^{13} \mathrm{C}, \mathrm{COSY}$, TOCSY, NOESY, HSQC, and HMBC sepctra (pages S38-S41).
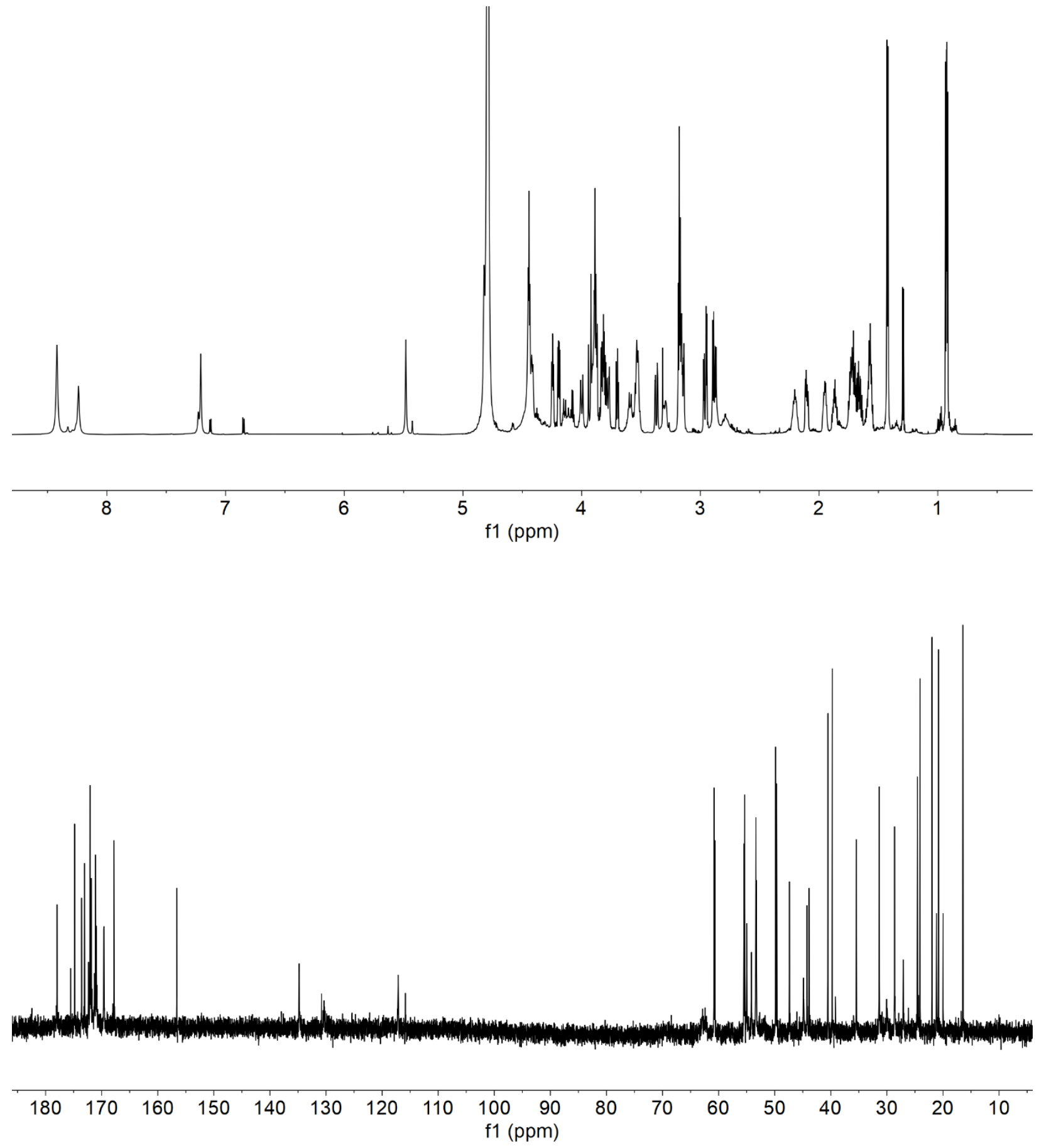

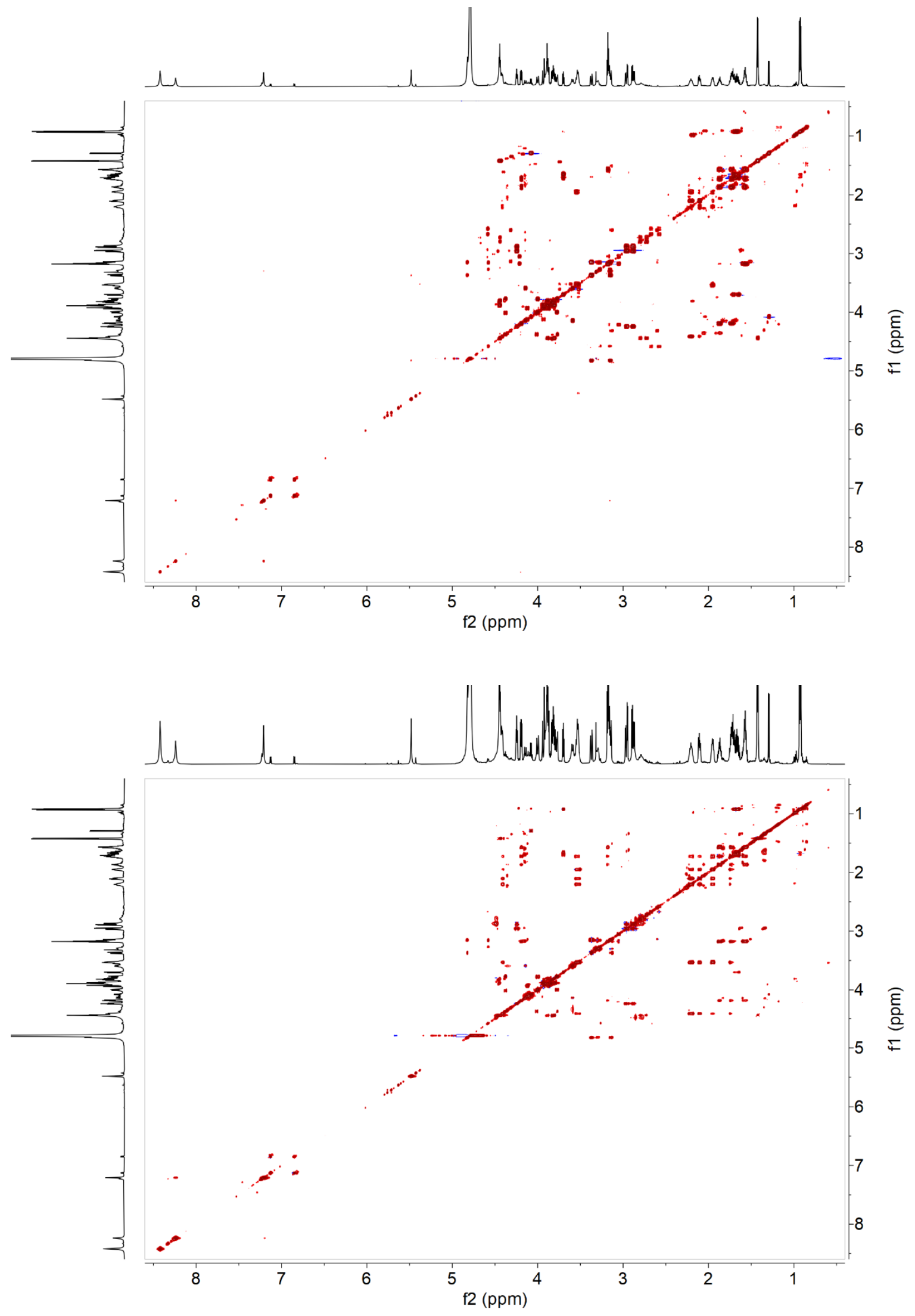

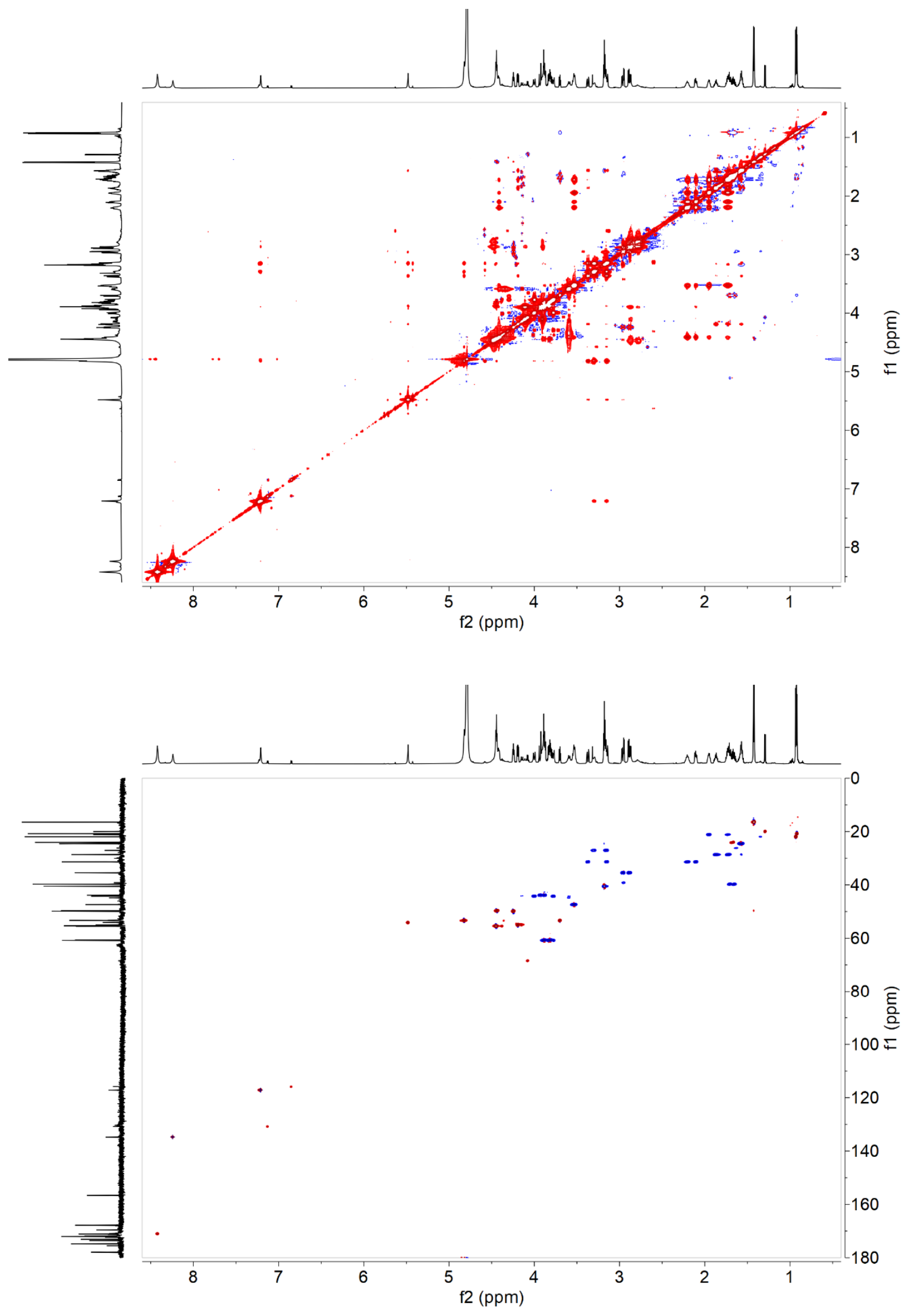


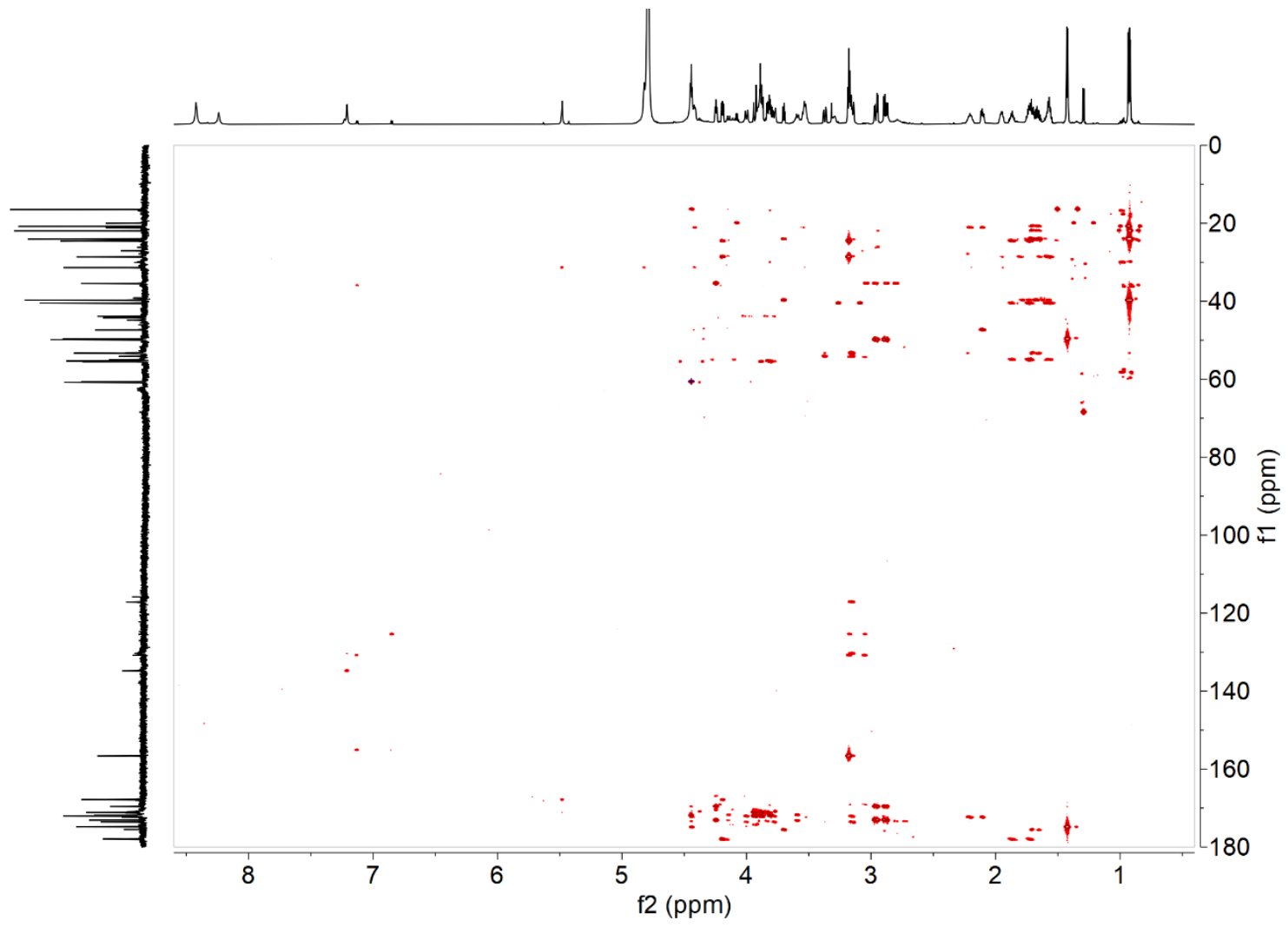


Figure S9. Clumping observed upon treatment of $S$. thermophilus JIM 8232 with high concentrations of streptosactin. Shown are images of $S$. thermophilus JIM 8232 cultures grown in duplicate in CDM medium and treated with streptosactin. (Top) Duplicate cultures across the two rows contain $64-0.5 \mu \mathrm{g} / \mathrm{mL}$ streptosactin in 2-fold dilution steps (wells 2 through 9). Wells 10 and 11 are untreated control cultures, whereas 1 and 12 contain only CDM. Clumping is observed at 64 and $32 \mu \mathrm{g} / \mathrm{mL}$ and to a lesser extent at $16 \mu \mathrm{g} / \mathrm{mL}$. (Bottom) Magnified view of clumping observed at 64 and $32 \mu \mathrm{g} / \mathrm{mL}$ streptosactin from an independent experiment in duplicate cultures.
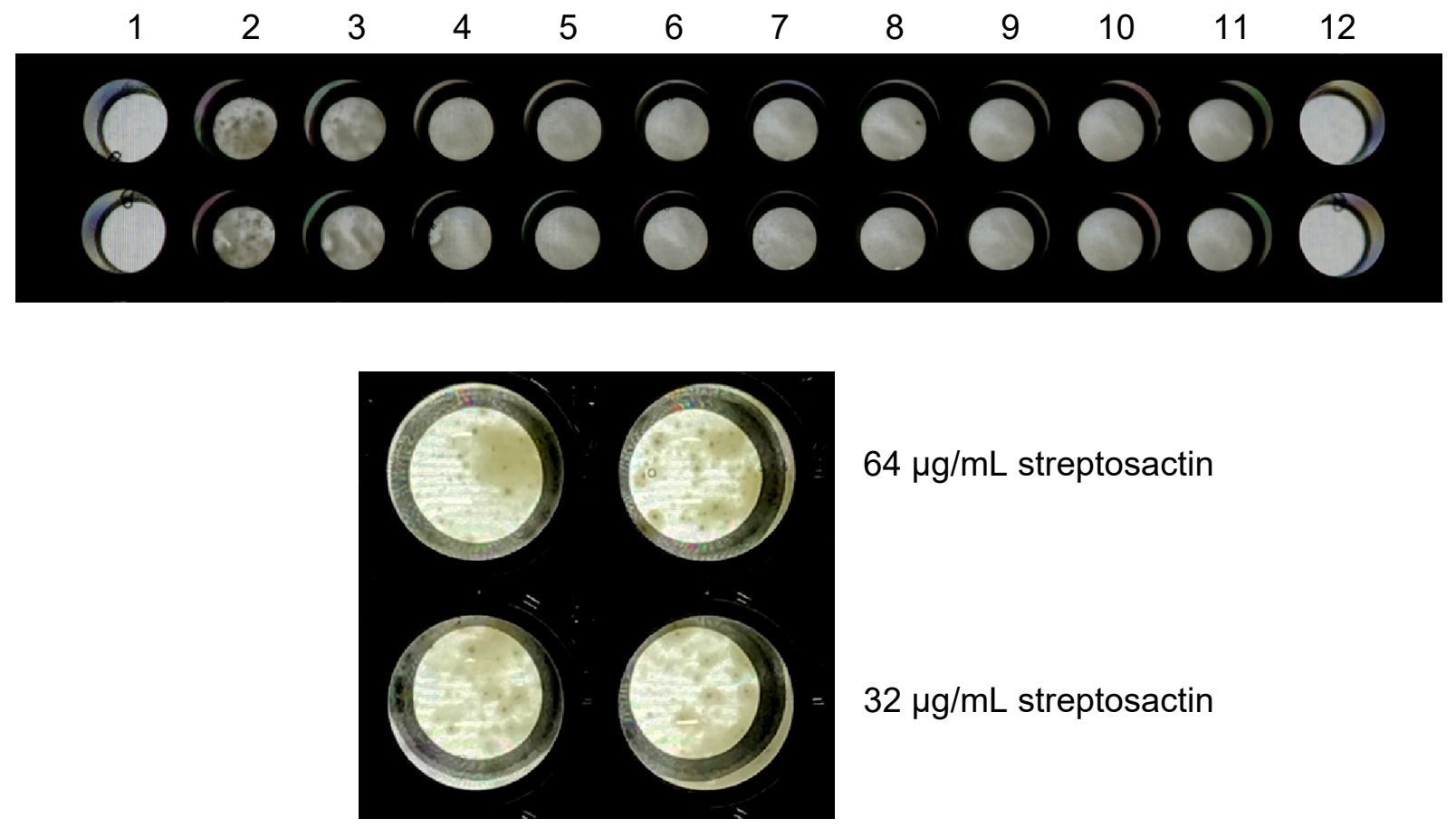

$64 \mu \mathrm{g} / \mathrm{mL}$ streptosactin

$32 \mu \mathrm{g} / \mathrm{mL}$ streptosactin 


\section{SI References}

(1) Bushin, L. B.; Seyedsayamdost, M. R. Guidelines for Determining the Structures of Radical SAM EnzymeCatalyzed Modifications in the Biosynthesis of RiPP Natural Products. Methods Enzymol. 2018, 606, 439-460.

(2) Barr, I.; Latham, J. A.; lavarone, A. T.; Chantarojsiri, T.; Hwang, J. D.; Klinman, J. P. Demonstration That the Radical S-Adenosylmethionine (SAM) Enzyme PqqE Catalyzes de Novo Carbon-Carbon Cross-Linking within a Peptide Substrate PqqA in the Presence of the Peptide Chaperone PqqD. J. Biol. Chem. 2016, 291, 88778884.

(3) Schramma, K. R.; Bushin, L. B.; Seyedsayamdost, M. R. Structure and Biosynthesis of a Macrocyclic Peptide Containing an Unprecedented Lysine-to-Tryptophan Crosslink. Nat. Chem. 2015, 7, 431-437.

(4) van de Rijn, I.; Kessler, R. E. Growth Characteristics of Group A Streptococci in a New Chemically Defined Medium. Infect. Immun. 1980, 27, 444-448.

(5) Chang, J. C.; LaSarre, B.; Jimenez, J. C.; Aggarwal, C.; Federle, M. J. Two Group A Streptococcal Peptide Pheromones Act through Opposing Rgg Regulators to Control Biofilm Development. PLoS Pathog. 2011, 7, e1002190.

(6) Tettelin, H.; Masignani, V.; Cieslewicz, M. J.; Donati, C.; Medini, D.; Ward, N. L.; Angiuoli, S. V.; Crabtree, J.; Jones, A. L.; Durkin, A. S.; DeBoy, R. T.; Davidsen, T. M.; Mora, M.; Scarselli, M.; Ros, I. M. y; Peterson, J. D.; Hauser, C. R.; Sundaram, J. P.; Nelson, W. C.; Madupu, R.; Brinkac, L. M.; Dodson, R. J.; Rosovitz, M. J.; Sullivan, S. A.; Daugherty, S. C.; Haft, D. H.; Selengut, J.; Gwinn, M. L.; Zhou, L.; Zafar, N.; Khouri, H.; Radune, D.; Dimitrov, G.; Watkins, K.; O’Connor, K. J. B.; Smith, S.; Utterback, T. R.; White, O.; Rubens, C. E.; Grandi, G.; Madoff, L. C.; Kasper, D. L.; Telford, J. L.; Wessels, M. R.; Rappuoli, R.; Fraser, C. M. Genome Analysis of Multiple Pathogenic Isolates of Streptococcus agalactiae: Implications for the Microbial "PanGenome." PNAS 2005, 102, 13950-13955.

(7) Sánchez-Beato, A. R.; García, E.; López, R.; García, J. L. Identification and Characterization of IS1381, a New Insertion Sequence in Streptococcus pneumoniae. J. Bacteriol. 1997, 179, 2459-2463.

(8) Bushin, L. B.; Clark, K. A.; Pelczer, I.; Seyedsayamdost, M. R. Charting an Unexplored Streptococcal Biosynthetic Landscape Reveals a Unique Peptide Cyclization Motif. J. Am. Chem. Soc. 2018, 140, 1767417684.

(9) Benahmed, F. H.; Gopinath, G. R.; Harbottle, H.; Cotta, M. A.; Luo, Y.; Henderson, C.; Teri, P.; Soppet, D.; Rasmussen, M.; Whitehead, T. R.; Davidson, M. Draft Genome Sequences of Streptococcus bovis Strains ATCC 33317 and JB1. Genome Announc. 2014, 2, e01012-14.

(10) Sulavik, M. C.; Tardif, G.; Clewell, D. B. Identification of a Gene, Rgg, Which Regulates Expression of Glucosyltransferase and Influences the Spp Phenotype of Streptococcus gordonii Challis. J. Bacteriol. 1992, 174, 3577-3586.

(11) Lowe, B. A.; Miller, J. D.; Neely, M. N. Analysis of the Polysaccharide Capsule of the Systemic Pathogen Streptococcus iniae and Its Implications in Virulence. Infect. Immun. 2007, 75, 1255-1264.

(12) Xu, H.; Sobue, T.; Bertolini, M.; Thompson, A.; Dongari-Bagtzoglou, A. Streptococcus oralis and Candida albicans Synergistically Activate $\mu$-Calpain to Degrade E-Cadherin From Oral Epithelial Junctions. J. Infect. Dis. 2016, 214, 925-934.

(13) Ajdić, D.; McShan, W. M.; McLaughlin, R. E.; Savić, G.; Chang, J.; Carson, M. B.; Primeaux, C.; Tian, R.; Kenton, S.; Jia, H.; Lin, S.; Qian, Y.; Li, S.; Zhu, H.; Najar, F.; Lai, H.; White, J.; Roe, B. A.; Ferretti, J. J. Genome Sequence of Streptococcus mutans UA159, a Cariogenic Dental Pathogen. PNAS, 2002, 99, 1443414439.

(14) Paulsen, I. T.; Banerjei, L.; Hyers, G. S. A.; Nelson, K. E.; Seshadri, R.; Read, T. D.; Fouts, D. E.; Eisen, J. A.; Gill, S. R.; Heidelberg, J. F.; Tettelin, H.; Dodson, R. J.; Umayam, L.; Brinkac, L.; Beanan, M.; Daugherty, S.; DeBoy, R. T.; Durkin, S.; Kolonay, J.; Madupu, R.; Nelson, W.; Vamathevan, J.; Tran, B.; Upton, J.; Hansen, T.; Shetty, J.; Khouri, H.; Utterback, T.; Radune, D.; Ketchum, K. A.; Dougherty, B. A.; Fraser, C. M. Role of Mobile DNA in the Evolution of Vancomycin-Resistant Enterococcus faecalis. Science 2003, 299, $2071-2074$.

(15) Davis, K. M.;Schramma, K. R.; Hansen, W. A.; Bacik, J. P.; Khare, S. D.; Seyedsayamdost, M. R.; Ando, N. Structures of the peptide-modifying radical SAM enzyme SuiB elucidate the basis of substrate recognition. Proc. Natl. Acad. Sci. USA 2017, 114, 10420-10425. 